\title{
Complutum
}

ISSN: 1131-6993

\section{Análisis compositivo y de profundidad de los grabados de la estela de Luna- Valpalmas mediante digitalización 3D por luz estructurada}

\author{
Andrés García-Arilla Oliver ${ }^{1}$, Héctor Conget Vicente ${ }^{2}$, Alejandro Moreno Terré ${ }^{3}$ y Óscar Pueyo Anchuela ${ }^{4}$
}

Recibido: 16/02/2021 / Aceptado: 27/04/2021

Resumen: Los motivos grabados en las llamadas estelas de guerrero o del suroeste han sido tratados desde un punto de vista iconográfico y solo recientemente se ha prestado atención a la secuencia y la técnica de elaboración. Siguiendo esta línea de investigación se aborda el estudio de la profundidad de los grabados de la estela de Luna-Valpalmas mediante la técnica de digitalización 3D por luz estructurada. De las lecturas se realiza una interpretación de la secuencia de creación de los mismos y su relación con el soporte en términos de diacronía y sincronía, verticalidad u horizontalidad. Palabras Clave: Estela de Luna-Valpalmas; digitalización 3D; estelas de guerrero; Bronce Final; profundidad de grabado.

[en] Analysis of the composition and carving depth of the Luna-Valpalmas stela through structured light $3 \mathrm{D}$ scanning

\begin{abstract}
The engraved motifs on the so-called warrior or southwestern stelae have been mainly approached from an iconographical perspective, paying attention only in the past few years to the technical process and sequence. In this line of research, a study of the Luna-Valpalmas stela is approached here by means of structured light 3D scanning technology and focus on the carving depth. The data obtained are read to determine a sequence of engraving of the motifs on the slab -diachronic or synchronic- and the intended position of the stela-vertical or horizontal-.
\end{abstract}

Key Words: Luna-Valpalmas Stela, 3D scanning, warrior stelae, Late Bronze Age, carving depth.

Sumario: 1. El estudio de las estelas de guerrero: presente y futuro de la investigación. 2. La estela de Luna-Valpalmas. 3. Estudio técnico del soporte y los grabados. 3.1 Caracterización petrográfica del soporte. 3.2. Metodología de la toma de datos: digitalización $3 \mathrm{~d}$ por luz estructurada para el estudio compositivo y de profundidad de los grabados. 3.3. Análisis de los motivos sobre el soporte. 3.4. Lectura arqueológica de las mediciones de profundidad de grabado. 3.4.1. La barbilla. 3.4.2. El escudo. 3.4.3. La lira. 4. Discusión. 5. Reflexión final. Bibliografía.

Cómo citar: García-Arilla Oliver, A.; Conget Vicente, H.; Moreno Terré, A.; Pueyo Anchuela, Ó. (2021): Análisis compositivo y de profundidad de los grabados de la estela de Luna-Valpalmas mediante digitalización 3D por luz estructurada. Complutum, 32(1): 49-71.

1 Arqueología y Didáctica Start Up Universidad de Zaragoza (investigadores independientes), Gran Vía 11 esc.D $4^{\circ} 1$ 50006, Zaragoza.

E-mail: garciarilla@gmail.com

2 Arqueología y Didáctica Start Up Universidad de Zaragoza (investigadores independientes), Gran Vía 11 esc.D $4^{\circ} 1$ 50006, Zaragoza.

E-mail: hconget@gmail.com

Tlf.: 615610215

3 Investigador independiente

E-mail: ales_moreno7@hotmail.com

4 Grupo de investigación Geotransfer. Instituto de Investigación en Ciencias Ambientales (IUCA), Universidad de Zaragoza. Calle de Pedro Cerbuna, 12, 50009 Zaragoza.

E-mail: opueyo@gmail.com 


\section{El estudio de las estelas de guerrero: presente y futuro de la investigación}

Las llamadas estelas de guerrero o estelas del suroeste conforman una de las manifestaciones más relevantes del final de la Edad del Bronce europea. Desde el descubrimiento en 1898 de los primeros ejemplares en Solana de Cabañas (Rosso de Luna, 1898) y Almendralejo (Marqués de Monsalud, 1898) las publicaciones monográficas de nuevos hallazgos han sido constantes, configurándose un corpus de más de ciento cuarenta ejemplares y una amplísima bibliografía desplegada en más de un siglo de investigaciones, entre las cuales destacan las obras de síntesis interpretativas de Almagro Basch (1966), Almagro Gorbea (1977), Varela y Pinho (1977), Barceló (1989), Galán (1994), Celestino (2001), Harrison (2004), Díaz-Guardamino (2010), Mederos Martín (2012) y Araque (2018).

Ante la falta de contextos arqueológicos, el estudio de las estelas se ha fundamentado principalmente en el análisis tipológico de los objetos representados en relación con materiales arqueológicos reales, su datación cronológica y la posible procedencia cultural de los mismos. La distribución espacial de las estelas en el cuadrante suroeste peninsular ha motivado su denominación y ha generado diversas interpretaciones sobre su funcionalidad: indicadores de tumbas de inhumación o incineración (Celestino, 2001), marcadores de vías de trashumancia regionales o límites fronterizos de entidades políticas (Galán, 1994), indicadores de presencia de recursos metalúrgicos (Mederos Martín, 2012), representación de tratantes de esclavos (Moreno Arrastio, 1998), indicadores de acuíferos (Araque, 2018).

Los hallazgos en la última década han desbordado la zona nuclear (Celestino, 2011): por el norte el ejemplar de Robleda en Salamanca (Martín Benito, 2010), la estela de Tojais en el norte de Portugal (Alves y Reis, 2011), llegando incluso por la fachada atlántica hasta el ejemplar de Pedra Alta en Castrelo do Val, Ourense (Santos-Estévez et al. 2017) y por el sur hasta Cádiz con el ejemplar reutilizado de Pocito Chico (López Amador, et al.2008).

La hipótesis sobre la función funeraria de las estelas, presente desde las primeras sínte- sis, ha pervivido, aunque ante la ausencia de restos materiales asociados ${ }^{5}$ ha sido matizada, considerando algunos autores su carácter como lugares de exposición de cadáveres, conmemorativos (Harrison, 2004) o cenotafios (Celestino, comunicación oral).

Recientemente, se ha abordado el problema integrándolo dentro del fenómeno de la erección de estelas a lo largo de toda la prehistoria peninsular y ha llamado la atención sobre la necesidad de considerar los soportes y sus grabados como elementos vivos y reinterpretados a lo largo de los siglos, es decir, atendiendo a la historia y los avatares de cada ejemplar individualizado (Díaz-Guardamino, 2010), así como al análisis más detallado de los microcontextos de aparición (García Sanjuán et al. 2006). En las últimas publicaciones se percibe un giro hacia la interpretación de los guerreros grabados en las estelas como divinidades (Celestino y López, 2006; Tejera Gaspar y Fernández Rodríguez, 2012: 112120; Araque, 2018: 246) o antepasados divinizados (Harrison, 2004: 114; Ruiz-Gálvez, 2019).

Resulta llamativo que las estelas solo hayan sido estudiadas desde el punto de vista de las técnicas de grabado en contadas ocasiones (Enríquez Navascués y Fernández Algaba, 2010; Celestino, 2001; García Sanjuán et al. 2006) y que aún no existan análisis basados en estudios experimentales, aspectos sobre los que, no obstante, se está profundizando recientemente a través de la relación entre la dureza de los soportes y las herramientas utilizadas (Araque, 2018:187-191) o mediante las ventajas que proporcionan las técnicas de digitalización a propósito de esta cuestión (Díaz-Guardamino et al. 2013, 2015, 2019; Díaz-Guardamino, 2020).

Entre la multiplicidad de puntos de vista en torno al fenómeno de las estelas, podemos definir tres axiomas que constituyen la base del consenso entre los investigadores:

- Las estelas del suroeste o estelas de guerrero, remiten en sus representaciones al imaginario de este. Bien se trate de la representación de un guerrero en sí, un personaje que hace uso de los elementos del guerrero de forma ostentatoria aunque no practique

Existen, sin embargo, algunas evidencias de materiales asociados que pudieran remitir tanto a la hipótesis funeraria como conmemorativa. Habitualmente se trata de contextos escasamente documentados (ver Galán y Ruiz-Gálvez, 1991, Díaz-Guardamino, 2010: 368 ss. Araque, 2018: 192-194) 
el arte de la guerra, bien de una divinidad a la cual se representa con los atributos del guerrero o bien se trate de un guerrero divinizado.

- Los grabados referentes a dicho imaginario se realizaron en el amplio lapso de tiempo en el que se conforman las manifestaciones culturales del Bronce Final - Primera Edad del Hierro peninsular, ya que las panoplias representadas se corresponden con elementos reales del registro arqueológico en diferentes ámbitos europeos durante este período. No obstante, se percibe cierta tendencia a descartar la Primera Edad del Hierro como marco cronológico de la erección de las estelas, momento en el cual su significado originario habría ya mutado.

- La interpretación de las estelas de guerrero o estelas del suroeste, como su propio nombre indica, está en estrecha relación con su posición geográfica en el cuadrante suroeste peninsular, zona de interacción de manifestaciones culturales atlánticas y mediterráneas. Por ello, el estudio de las escasas estelas de ámbitos geográficos denominados marginales resulta clave para comprender el fenómeno.

Respecto al devenir de las futuras investigaciones parece bastante aceptada la necesidad de seguir cuatro líneas de trabajo:

- El análisis de la historia de la pieza, incluyendo no solo información prehistórica sino también los avatares de su descubrimiento y vida posterior hasta el momento de su exposición museográfica si es que existe.

- El análisis de los microcontextos de aparición con el fin de precisar su función en el paisaje, mediante prospecciones intensivas, si es posible de carácter geofísico previa ubicación aproximada del hallazgo.

- El estudio tecnológico de la pieza deberá ser abordado mediante la contrastación de modelos digitales y producciones experimentales que permitan individualizar las características del grabado y de quien lo ejecutó, caracterizar la preparación de soportes, sistematizar técnicas y determinar herramientas utilizadas, buscar huellas de uso y transformaciones postdeposicionales, así como rastrear evidencias de pigmentación.

- La consideración de los objetos representados en las estelas, de los lugares de erección e incluso del propio acto técnico de grabado como signos, requiere el uso de herramientas conceptuales de la semiótica que permitan avanzar en cuestiones de interpretación de significado y funcionalidad, con un especial énfasis en las relaciones de indexación, aquellas más factibles de poder ser alcanzadas, dado que la creación y uso de la cultura material se haya inevitablemente condicionada por una red de significado social.

En una reciente publicación hemos abordado las dos primeras líneas: el estudio de la historia de la estela de Luna-Valpalmas desde las circunstancias de su hallazgo hasta los avatares sufridos por la pieza antes de su ingreso en los fondos del Museo Provincial de Zaragoza y una primera campaña de prospecciones geofísicas en la Tiñica del Royo, lugar de aparición de la estela (Conget y García-Arilla, 2017). En las líneas que siguen se aborda el estudio de la profundidad de los grabados de la estela de Luna-Valpalmas a través del análisis de los datos proporcionados mediante digitalización 3D por luz estructurada, de cuyas lecturas se realiza una interpretación acerca de la verticalidad/ horizontalidad del soporte durante la ejecución de los grabados y la sincronía/diacronía de los motivos representados.

\section{La estela de Luna-Valpalmas}

La estela de Luna-Valpalmas fue hallada durante las labores agrícolas desarrolladas en la finca Tiñíca del Royo (Luna, Zaragoza) durante los años setenta y depositada en el año 1975 en el Museo provincial de Zaragoza ${ }^{6}$. Desde un primer momento, y dada la presencia del grabado de un escudo con escotadura en $\mathrm{V}$, la pieza se integra en el conjunto de las estelas de guerrero (Fatás, 1975). El grabado de la lira como tal se reconocerá poco después, siendo la primera vez que se identifica

\footnotetext{
Tanto para las vicisitudes del hallazgo como para la elección de la denominación de la estela como Luna-Valpalmas consultar: Conget y García-Arilla, (2017): La estela de Luna-Valpalmas en su contexto territorial: Primera campaña de prospecciones geomagnéticas en la Tiñica del Royo. Salduie Nº17, Estudios de Prehistoria y Arqueología. Universidad de Zaragoza.
} 
la presencia de un cordófono en la serie (Bendala, 1977) e inaugurando una enconada discusión sobre la procedencia del instrumento (Bendala, 1983; Blázquez, 1983), en el ámbito helénico o fenicio. Posteriormente, desde la musicología se propuso un tercer origen para el instrumento en el ámbito centroeuropeo (Álvarez, 1985, 1990). La forma de la caja, la determinación del número de cuerdas o la posible presencia de una varilla cordal son los argumentos esgrimidos por los diver- sos autores para decantarse por una $\mathrm{u}$ otra procedencia. La estela de Luna-Valpalmas ha sido citada por diversos autores especialmente en relación con las posibilidades interpretativas que proporciona el detallado grabado de la lira (Fatás, 1983; Almagro, 1992; Mederos, 1996; Almagro, 2002; Díaz-Guardamino, 2010; Andrés, 2014; Jiménez, 2012; Santos 2015; Gomá, 2018) pero nunca se ha abordado su estudio desde un punto de vista arqueométrico.

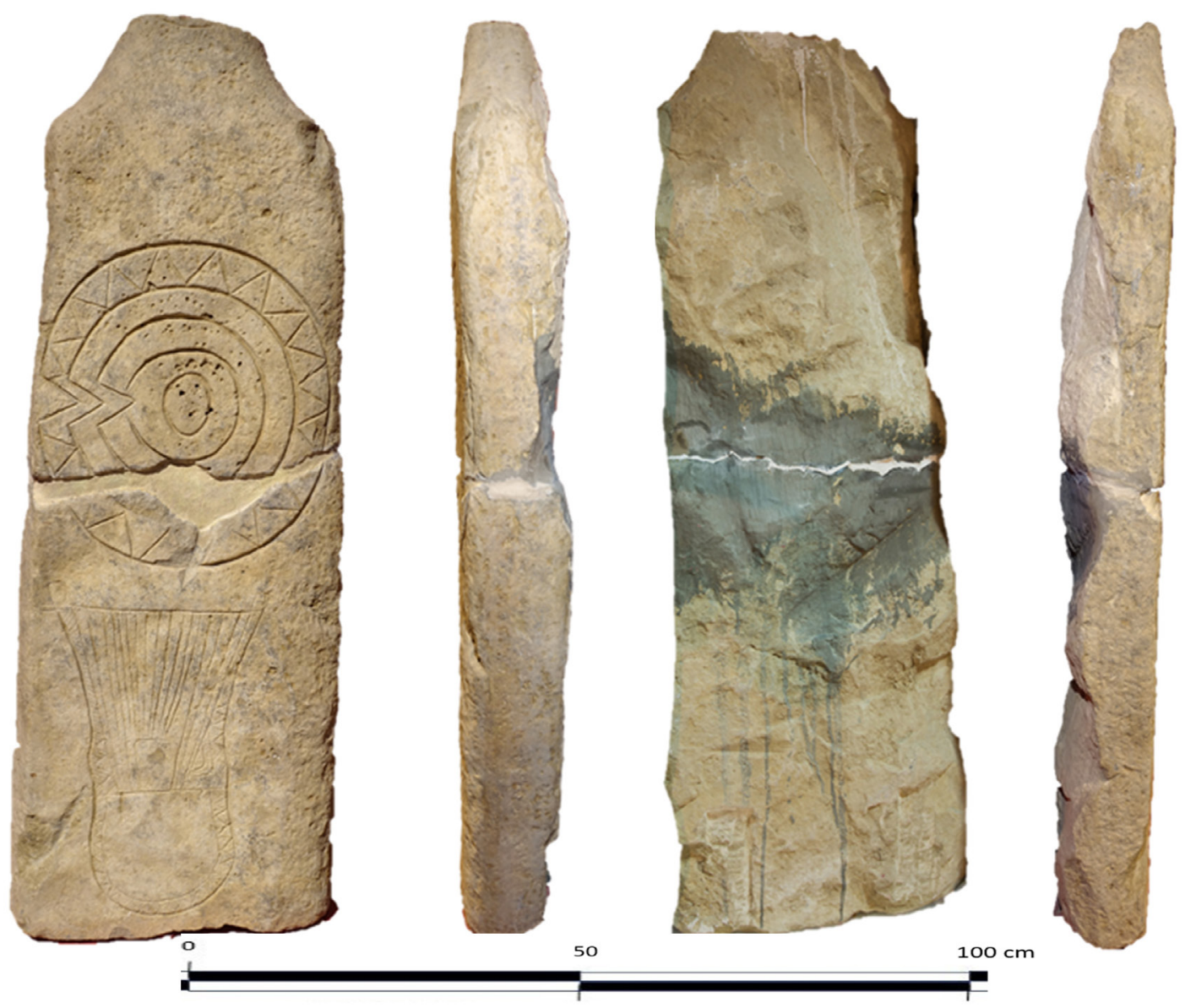

Figura 1. Estela de Luna-Valpalmas 


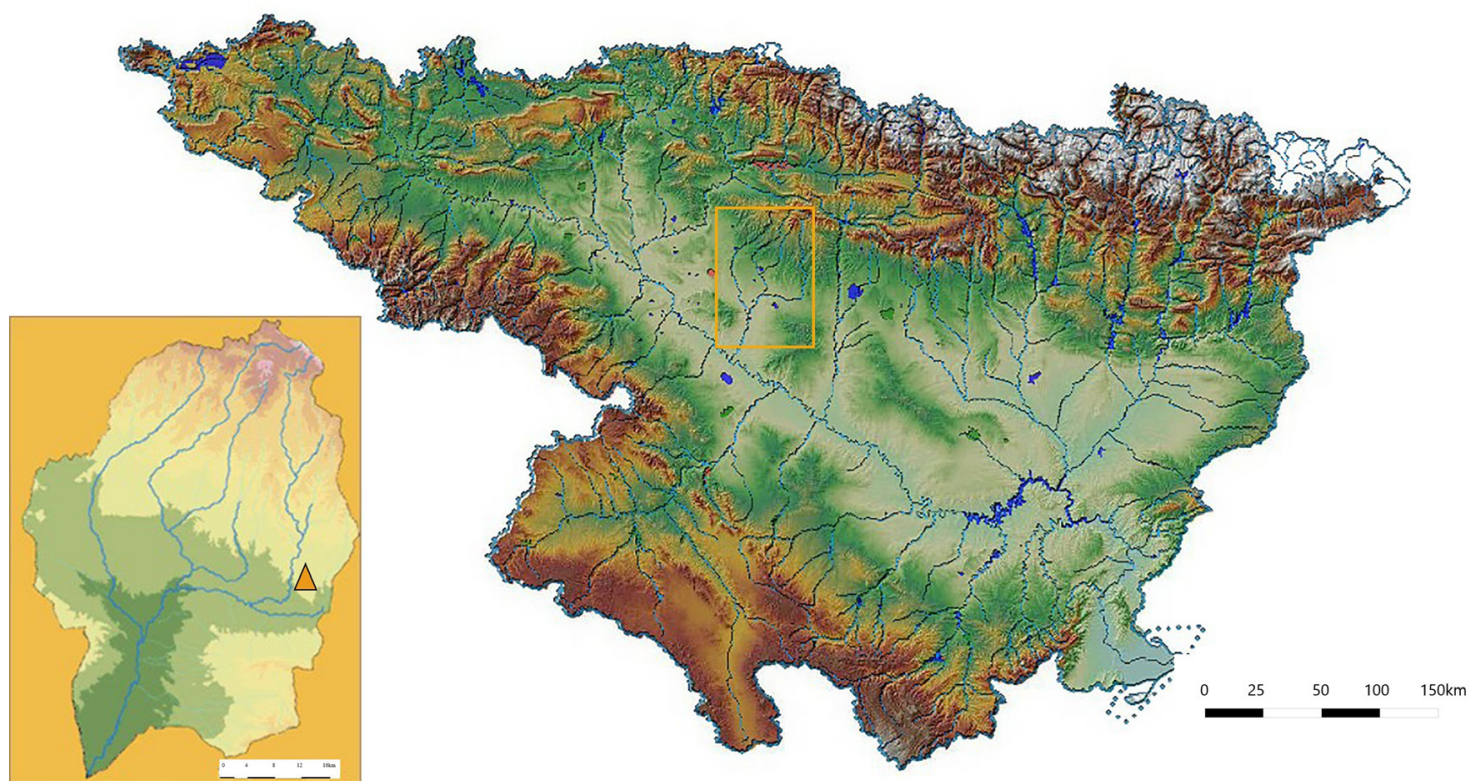

Figura 2. Localización del lugar de aparición de la estela de Luna-Valpalmas en la cuenca hidrográfica de los Arbas en el cuadrante noreste peninsular (modificación sobre imágenes de la Confederación hidrográfica del Ebro).

Constituye un ejemplar destacado en el conjunto de las estelas del suroeste por varias razones: Los grabados presentan un grado de perfección formal superior al resto de la serie, tanto por el detalle con que fue grabada la lira, como por la decoración sobre ambos grabados, hecho que en contadas ocasiones encontramos: Substantion, Buoux I o Ategua. El claro antropomorfismo del soporte solo sugerido por la disposición de los elementos grabados en otras estelas de tipo básico, es patente en la estela de Luna-Valpalmas y su posición marginal en el Valle del Ebro entre los escasos ejemplares del sureste francés y el núcleo del suroeste resultó clave en los modelos interpretativos de las vías de trashumancia suprarregionales (Ruiz Gálvez y Galán, 1991; Galán, 1994). La estela de Luna-Valpalmas no tiene representación de armas ofensivas y posee una composición de elementos única, ya que se trata de la única estela básica en la cual el objeto adicional se encuentra al mismo nivel de jerarquía compositiva que el escudo. La disposición de los motivos resulta relevante también para la discusión del uso de las estelas básicas en posición horizontal como losas sepulcrales, hecho que la contigüidad de la lira con la base del soporte podría evidenciar (Celestino, 2001) y que se opone a la opinión expresada por Galán, para el cual a la estela le falta un fragmento en la base que permitiría su posición erguida y por tanto la visibilidad del cordófono (1994).

\section{Estudio técnico del soporte y los grabados}

\subsection{Caracterización petrográfica del soporte}

Se realizaron láminas delgadas de una sección posterior de la Estela de Luna-Valpalmas y de la estela sin evidencias de grabado hallada en el moroño de la Tiñica del Royo durante la campaña de prospección realizada en el lugar de aparición de la estela de Luna-Valpalmas (Conget y García-Arilla, 2017) con el objetivo de su caracterización petrográfica. Se utilizó un microscopio petrográfico de polarización Olympus AX-70 y cámara fotográfica digital Olympus E-330. Ambas muestras están caracterizadas por arenitas granosostenidas donde predominan los cantos de cuarzo con morfología subangulosa (mayoritariamente monocristalinos; aunque puntualmente presentan extinción ondulante), cantos de feldespato (habitualmente alterados), filosilicatos detríticos (moscovíticos), fragmentos detríticos carbonatados y una matriz micrítica con cemento intergranular esparítico. El aspecto general de la matriz es oscuro y se identifican opacos en lámina delgada. La clasificación modal de am- 
bas rocas sería de una arenita -Litoarenita-sedarenita (Pettijohn et al.1987).

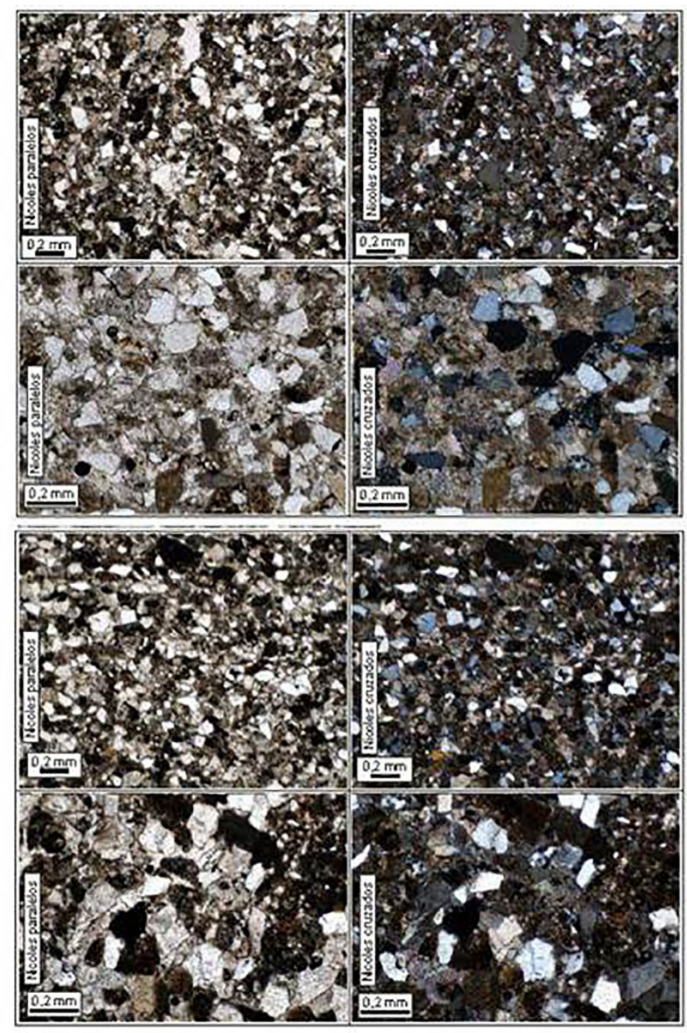

Figura 3. Abajo: Lámina delgada de la estela de Luna-Valpalmas. Arriba: Lámina delgada de la piedra hallada en el moroño durante las prospecciones realizadas en 2016. Derecha: nicoles cruzados. Izquierda: nicoles paralelos.

El análisis comparado de ambas muestras presenta ligeras diferencias que mantienen su clasificación y denotan un medio sedimentario de formación y condiciones diagenéticas similares: medio fluvial de baja energía similar a las rocas aflorantes en el entorno de la localización de la estela caracterizadas por paleocanales de areniscas, areniscas tabulares y arcillas (Unidad de Bujaraloz-Sariñena) y de paleocanales de areniscas y arcillas (Unidad de Remolinos-Lanaja), ambas de edad miocena. Las unidades aflorantes en el entorno del punto del hallazgo presentan características sedimentológicas similares como también texturales que son compatibles con medios fluviales de baja energía y depósitos de tipo point-bar (Arenas 1993; Salazar et al. 1995). Desde el punto de vista comparado ambas láminas no difieren significativamente y las variaciones son compatibles con cambios asociados dentro de la misma dinámica fluvial (ligera va- riación del contenido en fragmentos carbonatados entre ambas láminas), pero con misma área fuente y grado de transporte a partir de la clasificación del sedimento. Estos aspectos suponen que ambas muestras proceden de la misma unidad litológica y mismo contexto sedimentológico de formación que coincide con las características de las unidades aflorantes en el propio entorno del hallazgo. Es de interés señalar también el aspecto $a$ visu que permite identificar una coloración gris-verdosa que se debe a la presencia de pátinas de coloración verdosa. Estas pátinas son habituales en las rocas de esta edad de la zona y se asocian a mineralizaciones cupríferas de origen post-sedimentario (Cobres de Biel; ver, por ejemplo, Subías et al. 1989) que avalan también un potencial origen local de las muestras analizadas.

\subsection{Metodología de la toma de datos: Di- gitalización 3D por luz estructurada para el estudio compositivo y de profundidad de los grabados}

Las más recientes síntesis interpretativas sobre las estelas han llamado la atención sobre la necesidad de estudiar los soportes y grabados desde el punto de vista de las técnicas y herramientas utilizadas (Celestino, 2001:79-97; Araque, 2018: 187-191) y de aplicar metodologías usadas en el estudio del arte paleolítico (Díaz-Guardamino, 2010:345). Los estudios sobre arte paleolítico son pioneros en la aplicación de herramientas de digitalización del registro arqueológico, fruto de la necesidad de conservar lo mejor posible la información original, pero también de su potencial como herramienta para generar imágenes de segundo orden computerizadas, es decir, reducir la subjetividad y la toma de decisiones en la producción de imágenes que dependan lo menos posible de la pericia individual del investigador como dibujante, intérprete o fotógrafo (Montero et al.1998). Un corpus digitalizado abre sin lugar a dudas nuevas áreas de discusión.

A lo largo de esta última década se han realizado avances en el estudio de las representaciones gráficas gracias fundamentalmente a las siguientes técnicas de procesamiento digital: el SfM (Structure from Motion), que crea una nube de puntos a partir de múltiples capturas fotográficas, la fotogrametría, que parte del mismo principio pero difiere en la estrategia de trabajo, la RTI (Reflectance Transformation Imaging), que captura la incidencia de la luz 
sobre una superficie desde diferentes ángulos, el DIA (Digital Image Analysis), tratamiento a partir de una fotografía digital de una superficie para detectar pigmentos no visibles por el ojo humano y el escáner láser mediante luz estructurada, siendo este último el más costoso y más especializado. Es necesario conocer las ventajas e inconvenientes de cada técnica ${ }^{7}$ para saber cuál es la que mejor se ajusta a las necesidades de la investigación. El RTI y el escáner láser han sido utilizados en recientes trabajos sobre algunas estelas del suroeste (Diaz-Guardamino et al. 2013, 2015, 2019). La primera ha permitido detectar segmentos de trazos desgastados, borrados intencionados o reconocer diferentes técnicas de trabajo del soporte. El escáner láser por luz estructurada, la técnica elegida para el presente estudio, permite reconstruir con precisión submilimétrica la geometría de un objeto con el fin de obtener mediciones en cortes y perspectivas múltiples, por tanto idóneo para aproximarse a las características de los trazos que decoran las estelas, y formular hipótesis a partir de las lecturas arqueométricas ${ }^{8}$ sobre la secuencia de ejecución de los grabados, su diseño integral, el grado de maestría del grabador o grabadores o las herramientas empleadas. La técnica de digitalización mediante luz estructurada (Song Zhang y Peisen S. Huang, 2006) permite escanear la estela sin tener que utilizar medios de contacto físico directos. Se trata de una técnica que proyecta luz sobre el objeto a medir y mediante una cámara obtiene los datos necesarios para la reconstrucción en 3D. La sesión de digitalización se llevó a cabo en el Museo Provincial de Zaragoza, donde se encuentra actualmente la estela. La toma de datos se realizó mediante un escáner 3D SIDIO PRO2 ${ }^{9}$ de luz blanca, mesa de calibración y ordenador para el tratamiento de los datos obtenidos. Se llevó a cabo una configuración in situ con patrón para garantizar precisiones de calibración en el rango de trabajo en torno a los $0.020 \mathrm{~mm}$. El escanea- do se realizó en dos fases: En primer lugar, se digitalizó la parte superior de la pieza en la que se realizaron una serie de tomas desde diferentes perspectivas para garantizar una malla de calidad; en segundo lugar, la parte inferior. Una vez escaneada toda la superficie se comprobó en el ordenador de manera más minuciosa el resultado obtenido, procediendo a una segunda sesión sobre las zonas más críticas. Para asegurar la máxima calidad se aumentó el tiempo de exposición para garantizar la toma de datos de las zonas más sombreadas. Con la información obtenida en la sesión de escaneo se pasó al trabajo de reconstrucción obteniendo el modelo completo en alta calidad de la estela. Para ello se realizaron trabajos de edición de malla con el programa Polyworks ${ }^{10}$.

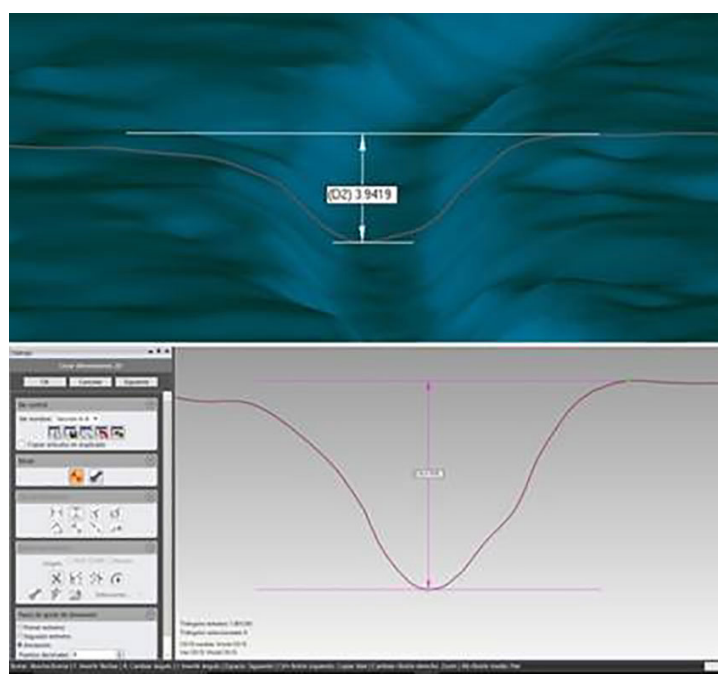

Figura. 4. Arriba: Imagen digitalizada de la superficie de un tramo del surco de grabado. Abajo:

Sección donde se muestra la cota 0 .

El resultado final fue un modelo reconstruido en formato STL cuya malla de polígonos se mejoró con el programa Geomagic Studio ${ }^{11}$ para su posterior estudio morfológico en detalle de las secciones con el módulo Qualify ${ }^{12}$. Debido a las irregularidades que forma la superficie de la

RTI permite detectar microhuellas en las superficies, DIA permite detectar pigmentos deteriorados y el SfM y la fotogrametría permite obtener, reconstruir y geoposicionar la geometría del objeto o territorio estudiado.

8 Consideramos que la obtención de mediciones numéricas a partir de la digitalización de objetos arqueológicos es un tipo de análisis cuantitativo y, por tanto, una información de carácter arqueométrico, dado que se enfrenta con los mismos procedimientos y problemas epistemológicos que los análisis físico-químicos (ver Montero et al., 2007: 24 y 29).

El Escáner 3D SIDIO Pro permite la medición de superficies en 3D para dar soporte a los procesos de diseño e ingeniería inversa, .(http://www.wr-cmm3d.com/Files/Name2/CONTENT59682d2cb5ea8315003904327510707226368675.pdf)

10 Polyworks es un programa para ingeniería inversa, control dimensional y manejo de datos recibidos desde escáner que permite convertir información de nubes de puntos a superficies tipo NURBS. (https://www.innovmetric.com/es)

11 Geomagic Studio es una aplicación de la marca 3D Systems de ingeniería inversa para la reconstrucción de geometrías 3D, actualmente Geomagic Design X (https://es.3dsystems.com/software/geomagic-design-x).

12 Geomagic Studio Qualify es un módulo para inspección y revisión de datos de modelos CAD 3D. 
estela y la complejidad de establecer un plano común o general a partir del que relacionar todas las medidas (plano 0), se decidió establecer una regla general que permitiera realizar una toma de datos coherente, estable, continua y homogénea de cada caso particular:

La profundidad total es la resultante entre la cota máxima más estable del modelo y la cota mínima. En el caso del punto más profundo no hay problema de interpretación, pero el punto más alto puede dar lugar a confusión ya que en cada recta estudiada la superficie varía levemente de unos modelos a otros debido a las imperfecciones de la superficie. Con este criterio se procedió a medir la profundidad de las secciones de los tramos elegidos de izquierda a derecha y de arriba a abajo. La distancia entre secciones se realizó en intervalos de un milímetro en las rectas y de un grado en los arcos.
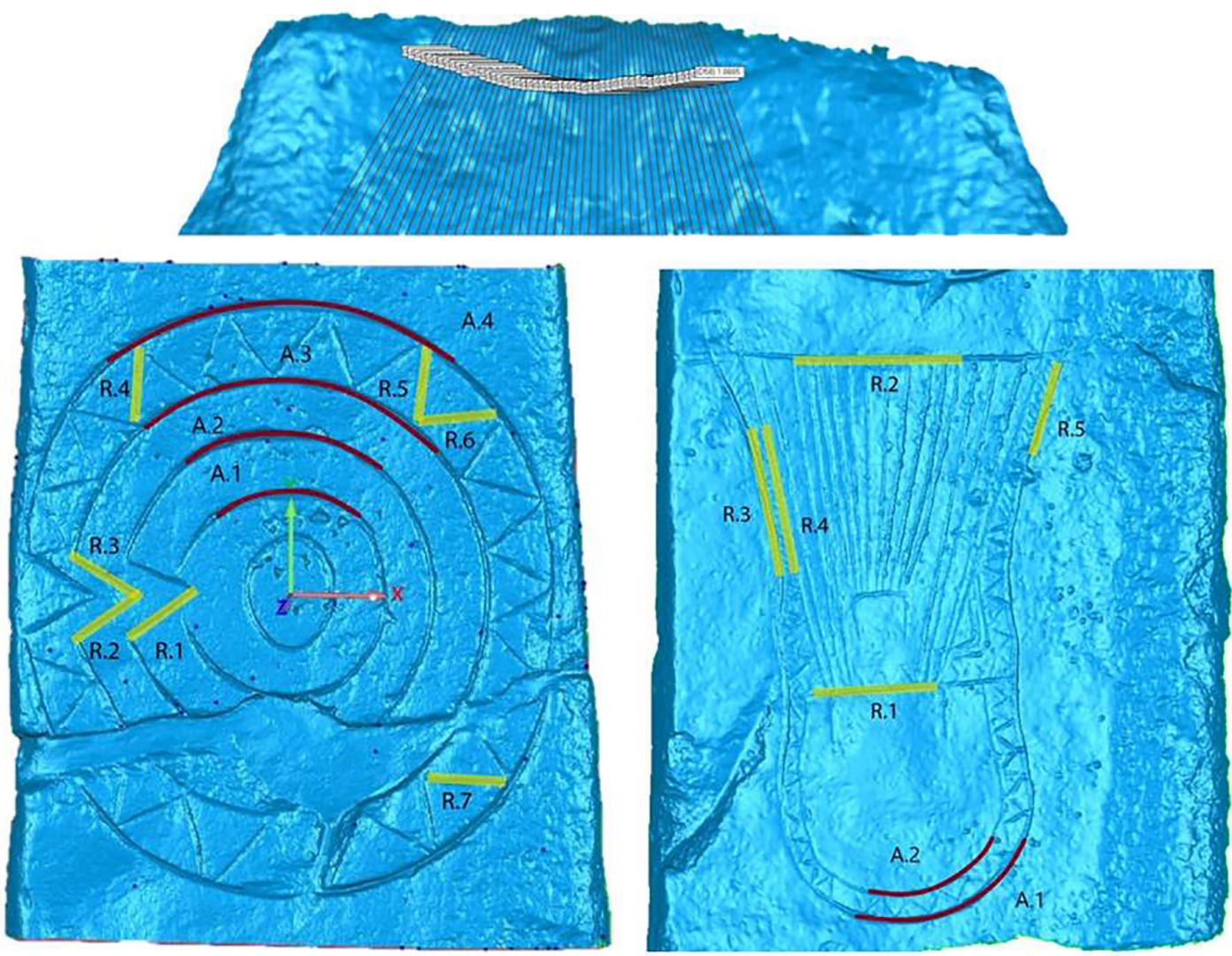

Figura 5. Segmentos de los grabados en los que se han hecho mediciones cada milímetro en las rectas (R) y cada grado en los arcos (A) según se muestra en el trazado de la barbilla.

\subsection{Análisis de los motivos sobre el soporte}

La estela de Luna-Valpalmas, de clara silueta antropomorfa, posee una serie de grabados realizados en la prehistoria y una serie de marcas postdeposicionales producidas por las labores agrícolas modernas (ver figura 6, abajo). Los grabados realizados sobre la estela de Luna-Valpalmas fueron hechos tras la prepa- ración de la superficie mediante pulimentado, lo que contrasta con su parte trasera sin pulir, aunque levemente desbastada. En su zona superior falta una parte que se presupone la cabeza que continúa los hombros del soporte y en su parte inferior la pieza está fracturada y falta un fragmento. Esta última cuestión resulta relevante en la controversia sobre la posición original de la estela, vertical u horizontal. 

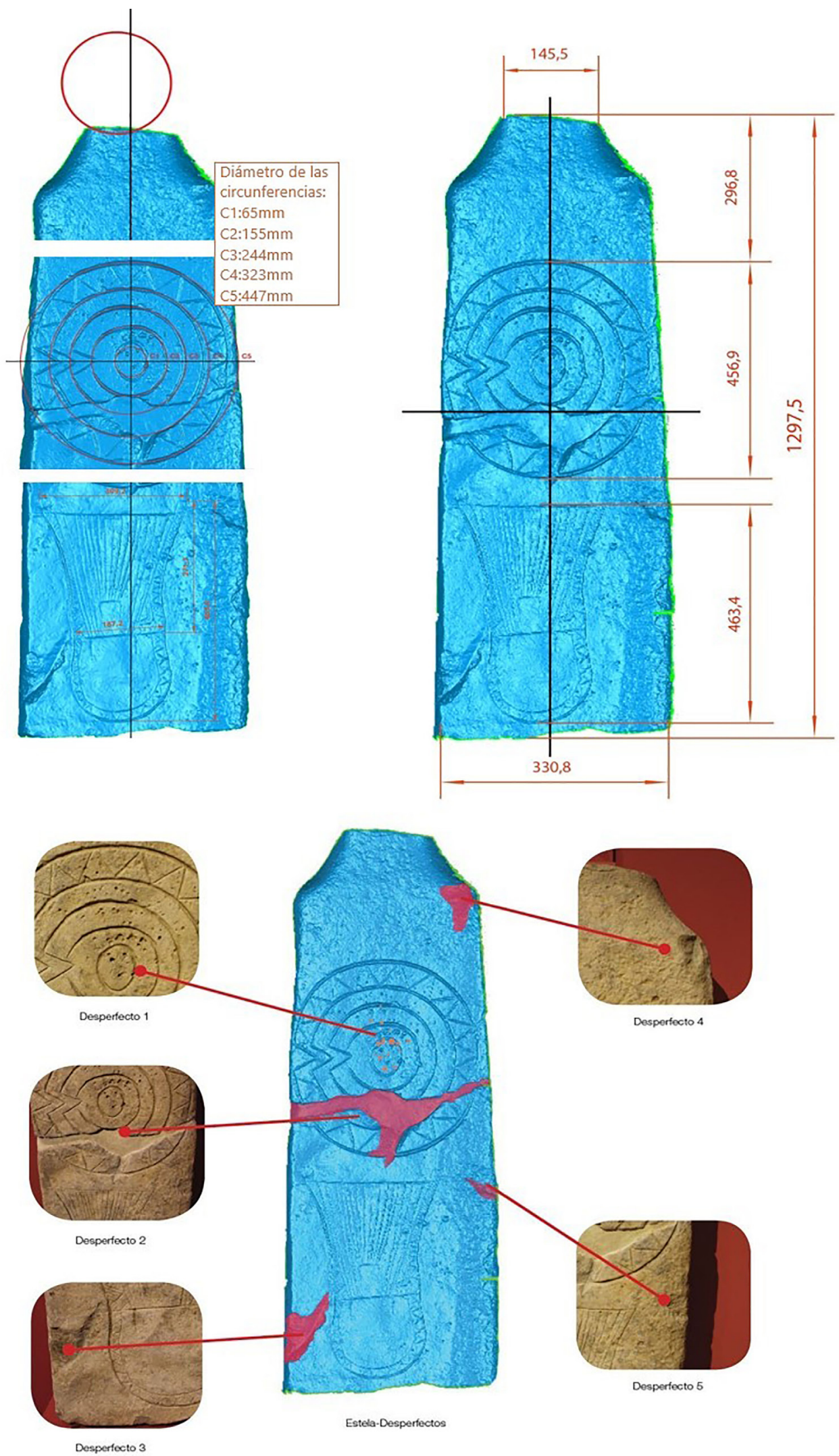

Figura 6. Arriba: Medidas de la estela de Luna-Valpalmas y de los motivos grabados. Proyección del óvalo facial. Se aprecia la gran variación de la simetría de los motivos con respecto al eje central del soporte. Abajo: Marcas postdeposicionales en la estela de Luna-Valpalmas. 
Como muestra la Figura 6, el escudo se encuentra simétrico en su eje longitudinal y colocado a la altura del pecho del soporte antropomorfo. De las cinco circunferencias concéntricas que lo componen, una de ellas (C3) es una circunferencia perfecta, lo que nos lleva a pensar que fue la primera en ser grabada como referencia para las demás, probablemente previo trazo con un elemento guía. La lira, por el contrario, se halla claramente desplazada hacia la izquierda del eje longitudinal, aunque su tamaño es similar al del escudo, y probablemente comenzó a ser grabada en su zona superior derecha. La atención otorgada por el grabador a la simetría de los objetos grabados en su relación con el soporte resulta notablemente desigual, indicio de que escudo y lira han sido realizados probablemente por diferente mano. Cuesta creer que la cuidada simetría del escudo respecto al soporte sea totalmente ignorada por el mismo grabador al afrontar la lira, máxime si tenemos en cuenta el más que probable uso de herramientas diferentes a juzgar por la diferente anchura y patrón de profundidad de surco entre motivos que analizaremos a continuación. El perfecto encaje del escudo respecto a la anchura del soporte nos lleva a pensar en la sincronía entre este grabado y el pulido del bloque por su parte delantera. Hombros y cabeza, marcadores del antropomorfismo del soporte son el resultado del mismo trabajo de abrasión, independientemente de que el soporte pueda haber sido reutilizado a partir de una estatua-menhir, que pudiera poseer forma antropomorfa y cierto desbaste en su parte trasera. El grabado de la lira se inició a partir de un trazo continuo de su contorno externo que es visiblemente más ancho, siendo posteriormente trazadas las líneas interiores. Su asimetría con respecto al bloque es un primer indicio de diacronía con respecto a la preparación del soporte y al escudo, pese a que los motivos decorativos triangulares presentes en ambos grabados pudieran indicar lo contrario. El pequeño trazo conservado de la barbilla nos ha permitido realizar una proyección del tamaño del óvalo facial. Aunque sería presumible que este grabado se realizará al mismo tiempo que la preparación del soporte antropomorfo y de forma sincrónica al escudo, los datos aportados por el análisis de luz estructurada de este pequeño trazo, nos conduce a patrones similares a los de la lira, como veremos en el apartado siguiente.

\subsection{Lectura arqueológica de las mediciones de profundidad de grabado}

Los datos de profundidad de surco proporcionados por el análisis de luz estructurada son interpretados tecnológicamente a partir de las similitudes y contrastes obtenidos entre los tres motivos representados (escudo, lira y barbilla), por similitudes y contrastes de los tramos analizados de cada uno de los motivos de forma independiente y a la relación de todos ellos respecto a la posición en el soporte en términos de verticalidad u horizontalidad. En un principio se decidió dirigir los análisis hacia varias curvas y rectas de ambos objetos con el fin de definir fundamentalmente el tipo de herramienta utilizada por el grabador. Sin embargo, las lecturas de los datos obtenidos condujeron la investigación hacia el análisis de otros tramos que resultaron ser relevantes para la inferencia arqueológica en la oposición entre tramos longitudinales y transversales al soporte.

\begin{tabular}{|c|c|c|}
\hline \multicolumn{3}{|c|}{ SECCIONES } \\
\hline & Arcos & Rectas \\
\hline \multirow{8}{*}{$\begin{array}{l}\text { Barbilla } \\
\text { Escudo }\end{array}$} & 49 (A1) & \\
\hline & 91 (A1) & 49 (R1) \\
\hline & $91(\mathrm{~A} 2)$ & $42(\mathrm{R} 2)$ \\
\hline & $91(\mathrm{~A} 3)$ & $45(\mathrm{R} 3)$ \\
\hline & 91 (A4) & 39 (R4) \\
\hline & & 39 (R5) \\
\hline & & 46 (R6) \\
\hline & & 49 (R7) \\
\hline \multirow{5}{*}{ Lira } & $48(\mathrm{~A} 1)$ & 79 (R1) \\
\hline & 48 (A2) & 98 (R2) \\
\hline & & 79 (R3) \\
\hline & & 79 (R4) \\
\hline & & 54 (R5) \\
\hline
\end{tabular}

Tabla 1. Número de secciones del muestreo y denominación del conjunto al que pertenecen.

\subsubsection{La barbilla}

Del único trazo que se conserva de lo que se presupone la barbilla de un óvalo facial se han tomado 49 secciones. En términos generales se trata de valores poco profundos en relación a la totalidad de los grabados y similares a los tomados en los arcos de la lira, precisamente aquellos trazos de la lira que se encuentran en la misma orientación que la barbilla respecto al soporte. Este hecho sumado a la apreciación 
de que el óvalo facial y la lira se encuentran ambos desplazados de forma significativa a la izquierda del eje del soporte, indican la proba- ble ejecución de ambos motivos por una misma mano, y con el soporte en una misma posición.

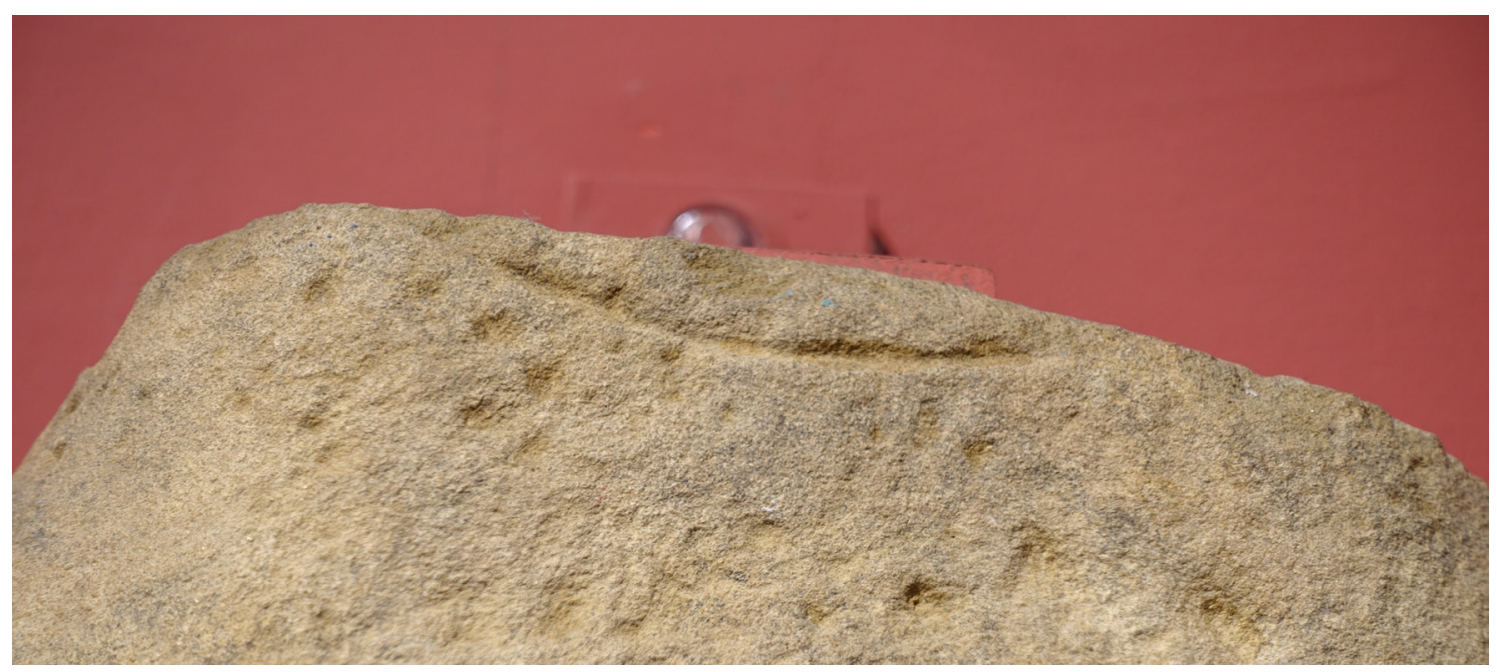

Figura 7. Trazo de la barbilla

\begin{tabular}{|c|c|c|c|}
\hline Número & Profundidad & Número & Profundidad \\
\hline Sección 1 & 0,62 & Sección 26 & 1,21 \\
\hline Sección 2 & 0,51 & Sección 27 & 0,95 \\
\hline Sección 3 & 0,55 & Sección 28 & 0,85 \\
\hline Sección 4 & 0,52 & Sección 29 & 0,91 \\
\hline Sección 5 & 0,69 & Sección 30 & 0,93 \\
\hline Sección 6 & 0,90 & Sección 31 & 0,96 \\
\hline Sección 7 & 1,12 & Sección 32 & 1,16 \\
\hline Sección 8 & 1,20 & Sección 33 & 1,16 \\
\hline Sección 9 & 1,06 & Sección 34 & 1,30 \\
\hline Sección 10 & 0,72 & Sección 35 & 1,29 \\
\hline Sección 11 & 0,77 & Sección 36 & 1,33 \\
\hline Sección 12 & 0,75 & Sección 37 & 1,40 \\
\hline Sección 13 & 1,26 & Sección 38 & 1,40 \\
\hline Sección 14 & 1,11 & Sección 39 & 1,20 \\
\hline Sección 15 & 0,90 & Sección 40 & 1,13 \\
\hline Sección 16 & 0,79 & Sección 41 & 1,07 \\
\hline Sección 17 & 0,76 & Sección 42 & 1,06 \\
\hline Sección 18 & 0,74 & Sección 43 & 0,96 \\
\hline Sección 19 & 0,51 & Sección 44 & 0,80 \\
\hline Sección 20 & 0,75 & Sección 45 & 0,58 \\
\hline Sección 21 & 0,48 & Sección 46 & 0,92 \\
\hline Sección 22 & 0,71 & Sección 47 & 1,03 \\
\hline Sección 23 & 0,97 & Sección 48 & 1,11 \\
\hline Sección 24 & 1,18 & Sección 49 & 1,07 \\
\hline Sección 25 & 1,25 & & \\
\hline
\end{tabular}

Tabla 2. Secciones en milímetros del arco de la barbilla. 


\begin{tabular}{|c|c|c|c|c|}
\hline & Profundidad & Profundidad & Profundidad & Profundidad \\
\hline Número & Arco 1 & Arco 2 & Arco 3 & Arco 4 \\
\hline Sección 1 & 4,97 & 3,02 & 4,09 & 3,38 \\
\hline Sección 2 & 4,76 & 3,04 & 4,42 & 3,67 \\
\hline Sección 3 & 4,47 & 3,07 & 4,23 & 3,64 \\
\hline Sección 4 & 4,31 & 3,25 & 3,49 & 3,97 \\
\hline Sección 5 & 4,64 & 3,52 & 3,55 & 4,20 \\
\hline Sección 6 & 4,54 & 3,60 & 4,07 & 4,29 \\
\hline Sección 7 & 4,79 & 4,46 & 4,44 & 4,54 \\
\hline Sección 8 & 5,10 & 3,92 & 4,01 & 3,98 \\
\hline Sección 9 & 4,83 & 4,12 & 4,60 & 3,79 \\
\hline Sección 10 & 4,59 & 4,18 & 4,59 & 3,33 \\
\hline Sección 11 & 4,33 & 4,49 & 5,02 & 3,66 \\
\hline Sección 12 & 4,59 & 4,60 & 3,60 & 4,03 \\
\hline Sección 13 & 4,56 & 4,54 & 4,90 & 3,93 \\
\hline Sección 14 & 4,49 & 4,43 & 4,42 & 4,37 \\
\hline Sección 15 & 4,52 & 4,08 & 4,60 & 4,99 \\
\hline Sección 16 & 4,23 & 4,04 & 4,23 & 4,78 \\
\hline Sección 17 & 4,59 & 4,25 & 3,92 & 5,17 \\
\hline Sección 18 & 4,80 & 4,46 & 3,94 & 5,32 \\
\hline Sección 19 & 4,92 & 4,79 & 3,64 & 5,40 \\
\hline Sección 20 & 5,00 & 5,31 & 3,19 & 5,17 \\
\hline Sección 21 & 5,05 & 5,44 & 3,33 & 4,95 \\
\hline Sección 22 & 5,01 & 5,74 & 4,05 & 4,96 \\
\hline Sección 23 & 5,19 & 6,04 & 4,80 & 5,63 \\
\hline Sección 24 & 5,28 & 6,28 & 5,16 & 4,35 \\
\hline Sección 25 & 5,46 & 5,98 & 5,43 & 4,41 \\
\hline Sección 26 & 5,46 & 5,69 & 5,57 & 4,66 \\
\hline Sección 27 & 5,45 & 6,49 & 4,65 & 5,05 \\
\hline Sección 28 & 5,49 & 6,07 & 3,48 & 4,63 \\
\hline Sección 29 & 5,76 & 6,10 & 3,37 & 4,34 \\
\hline Sección 30 & 5,82 & 6,04 & 3,36 & 4,61 \\
\hline Sección 31 & 5,78 & 6,05 & 3,51 & 4,39 \\
\hline Sección 32 & 5,91 & 6,14 & 3,54 & 4,74 \\
\hline Sección 33 & 5,68 & 6,39 & 3,74 & 5,15 \\
\hline Sección 34 & 5,58 & 6,66 & 3,79 & 4,57 \\
\hline Sección 35 & 5,73 & 6,81 & 3,61 & 4,59 \\
\hline Sección 36 & 5,66 & 7,09 & 3,51 & 4,91 \\
\hline Sección 37 & 5,84 & 7,42 & 3,62 & 5,37 \\
\hline Sección 38 & 5,91 & 7,19 & 3,43 & 5,27 \\
\hline Sección 39 & 5,91 & 7,24 & 3,29 & 4,29 \\
\hline Sección 40 & 5,94 & 7,43 & 3,61 & 4,39 \\
\hline Sección 41 & 6,19 & 7,63 & 3,83 & 5,03 \\
\hline Sección 42 & 6,05 & 7,73 & 4,26 & 4,89 \\
\hline Sección 43 & 6,35 & 7,26 & 3,70 & 4,74 \\
\hline Sección 44 & 6,60 & 7,02 & 3,99 & 4,98 \\
\hline Sección 45 & 6,62 & 6,61 & 4,23 & 5,01 \\
\hline Sección 46 & 6,60 & 6,06 & 4,02 & 4,96 \\
\hline
\end{tabular}

\begin{tabular}{|c|c|c|c|c|}
\hline Sección 47 & 6,22 & 5,35 & 3,97 & 4,51 \\
\hline Sección 48 & 5,58 & 5,46 & 4,29 & 4,63 \\
\hline Sección 49 & 5,50 & 5,49 & 4,48 & 4,57 \\
\hline Sección 50 & 6,32 & 5,33 & 4,64 & 4,48 \\
\hline Sección 51 & 5,97 & 5,17 & 4,59 & 4,64 \\
\hline Sección 52 & 6,23 & 5,01 & 4,73 & 5,04 \\
\hline Sección 53 & 6,15 & 5,16 & 5,33 & 5,12 \\
\hline Sección 54 & 5,96 & 4,84 & 5,56 & 4,69 \\
\hline Sección 55 & 5,77 & 4,97 & 4,89 & 4,78 \\
\hline Sección 56 & 5,36 & 4,78 & 4,68 & 5,27 \\
\hline Sección 57 & 5,54 & 3,98 & 4,03 & 5,71 \\
\hline Sección 58 & 5,73 & 3,54 & 3,60 & 5,50 \\
\hline Sección 59 & 5,38 & 4,40 & 4,51 & 5,80 \\
\hline Sección 60 & 5,79 & 3,18 & 3,49 & 5,39 \\
\hline Sección 61 & 5,94 & 2,87 & 2,83 & 5,30 \\
\hline Sección 62 & 5,67 & 2,85 & 4,18 & 5,50 \\
\hline Sección 63 & 5,44 & 2,94 & 3,76 & 5,21 \\
\hline Sección 64 & 5,41 & 2,63 & 3,00 & 4,99 \\
\hline Sección 65 & 5,16 & 2,75 & 3,05 & 4,82 \\
\hline Sección 66 & 4,90 & 2,55 & 3,14 & 4,94 \\
\hline Sección 67 & 4,19 & 2,09 & 3,16 & 5,01 \\
\hline Sección 68 & 4,80 & 2,65 & 3,48 & 4,80 \\
\hline Sección 69 & 4,93 & 2,67 & 3,69 & 5,17 \\
\hline Sección 70 & 4,80 & 2,81 & 3,81 & 4,93 \\
\hline Sección 71 & 4,82 & 3,19 & 3,90 & 5,50 \\
\hline Sección 72 & 4,60 & 3,55 & 3,62 & 5,05 \\
\hline Sección 73 & 4,37 & 3,69 & 4,05 & 4,76 \\
\hline Sección 74 & 4,33 & 3,26 & 4,08 & 4,78 \\
\hline Sección 75 & 4,36 & 3,16 & 5,28 & 5,11 \\
\hline Sección 76 & 4,56 & 3,07 & 4,38 & 4,99 \\
\hline Sección 77 & 4,77 & 2,73 & 4,27 & 4,86 \\
\hline Sección 78 & 4,73 & 2,64 & 4,05 & 4,82 \\
\hline Sección 79 & 4,77 & 2,67 & 3,94 & 4,68 \\
\hline Sección 80 & 4,45 & 2,91 & 3,13 & 4,72 \\
\hline Sección 81 & 4,30 & 3,13 & 4,36 & 4,59 \\
\hline Sección 82 & 4,09 & 3,17 & 4,17 & 4,66 \\
\hline Sección 83 & 3,97 & 3,30 & 3,96 & 4,62 \\
\hline Sección 84 & 4,01 & 3,15 & 4,44 & 4,75 \\
\hline Sección 85 & 3,79 & 3,02 & 4,44 & 4,95 \\
\hline Sección 86 & 3,59 & 2,91 & 4,43 & 4,65 \\
\hline Sección 87 & 3,66 & 3,05 & 4,68 & 4,86 \\
\hline Sección 88 & 3,74 & 3,21 & 4,91 & 4,74 \\
\hline Sección 89 & 3,84 & 3,10 & 4,73 & 4,60 \\
\hline Sección 90 & 3,87 & 3,04 & 4,45 & 5,15 \\
\hline Sección 91 & 3,89 & 2,93 & 4,35 & 5,18 \\
\hline
\end{tabular}

Tabla 3. Secciones en milímetros de los arcos A1, A2, A3 y A4 del escudo.

\subsection{El escudo}

En el escudo se han realizado lecturas sobre siete rectas y cuatro arcos. Con un total de 673 secciones. Lo primero que llama la atención de los valores tomados en el escudo es que son mucho más profundos que los de la lira y la barbilla. Es interesante resaltar que los trazos de las circunferencias del escudo son considerablemente más profundos que en las rectas que configuran los motivos decorativos y la escotadura. Se puede apreciar que en cuatro de 
las siete rectas (ver tabla 6) las secciones menos profundas son la 1, ello se debe a que al estar muy cerca de la intersección con alguna de las circunferencias, el grabador tuvo especial cuidado en evitar que el vértice no saltara. La sección 1 de las rectas 1, 3, 6 y 7 se inician acercándose al punto de dicha intersección. Por lo tanto, podemos describir una secuencia de grabado del escudo que se inicia en la circunferencia perfecta $\mathrm{C} 3$ (A2) con los valores más extremos. Continúa trazando los círculos concéntricos de considerable profundidad, sin poder determinar en qué orden y finaliza con los triángulos decorativos de valores menores y una ejecución precavida para evitar daños en las circunferencias previamente trazadas. El ejemplo más claro de este punto es la ejecución de C2 de forma posterior a C3. Que la escotadura de C3 estaba realizada cuando se realizó C2 queda patente en el hecho de que el grabador evita el lascado que se hubiera producido si C2 hubiera interceptado la recta a mitad de la escotadura de $\mathrm{C} 3$. El trazado de $\mathrm{C} 2$ se produce en el sentido de las agujas del reloj dado que el grabador, sin partir de ella, aproxima mucho más el círculo a la escotadura cuando ataca una zona firme, libre de surco previo y lo deja mucho más distante cuando ataca una zona ocupada por el surco de la escotadura, como ocurre en la zona inferior de la escotadura de C3, único lugar de todo el escudo donde el grabado llega prácticamente a interrumpirse.

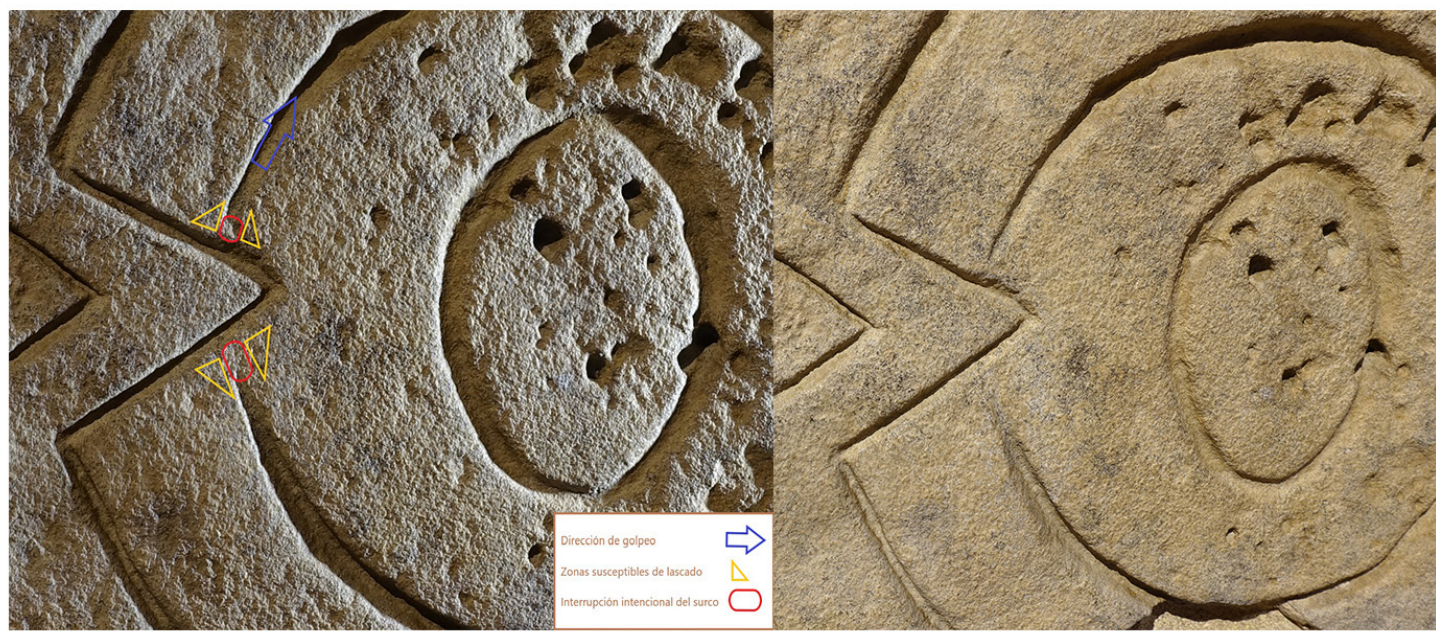

Figura 8. Escudo. Detalle del surco de C2 en relación a la escotadura del C3.

La ejecución de los triángulos que decoran el espacio entre $\mathrm{C} 4$ y C5 es posterior a la ejecución de los círculos,y se realizan desde el exterior hacia el interior tanto por el cuidado que el grabador tiene al interceptar el círculo previamente existente con las líneas de vértice de los triángu- los, como por la invasión de las líneas sobre las curvas como se muestra en el ejemplo de la figura 9.Esta huella que nos permite determinar la secuencia ha sobrevivido al probable repasado de las circunferencias que habitualmente truncan el vértice de muchos de los triángulos.

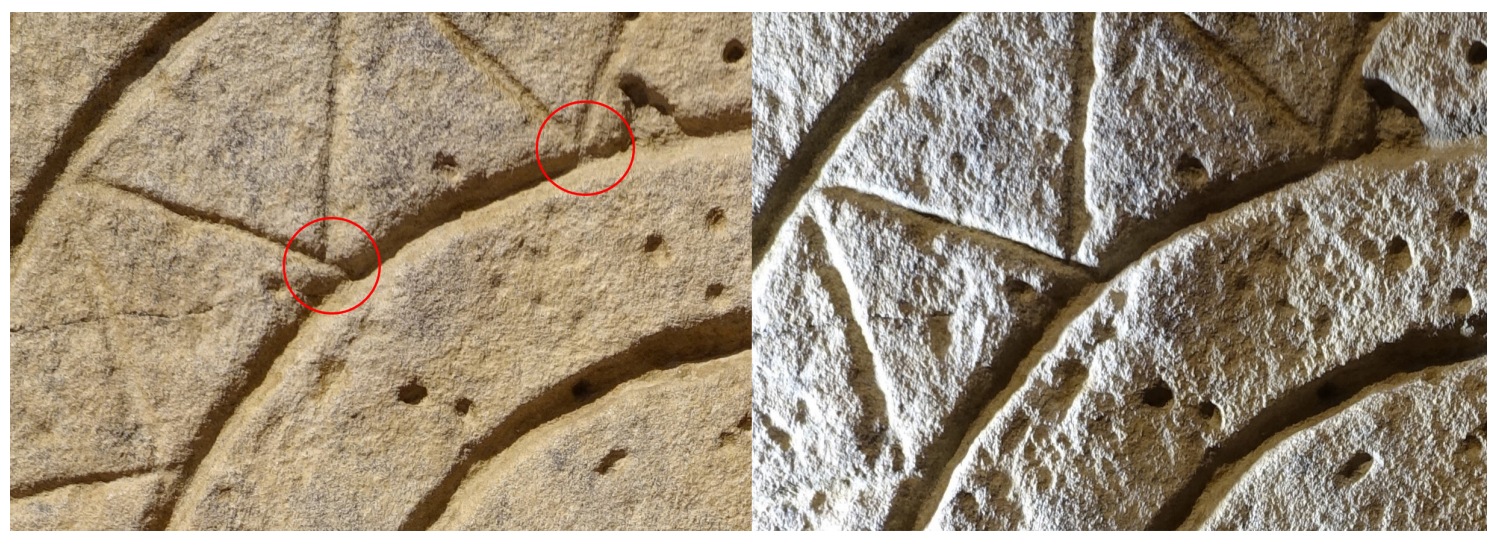

Figura 9. Escudo.Detalle de superposición en el trazado de triángulo decorativo con respecto a C4. 


\begin{tabular}{|c|c|c|}
\hline \multicolumn{3}{|c|}{ Profundidad (mm) } \\
\hline Número & Arco 1 & $\operatorname{Arco} 2$ \\
\hline Sección 1 & 1,52 & 0,68 \\
\hline Sección 2 & 1,95 & 0,75 \\
\hline Sección 3 & 1,61 & 0,65 \\
\hline Sección 4 & 1,69 & 0,57 \\
\hline Sección 5 & 1,65 & 0,55 \\
\hline Sección 6 & 1,81 & 0,50 \\
\hline Sección 7 & 1,53 & 0,42 \\
\hline Sección 8 & 1,40 & 0,48 \\
\hline Sección 9 & 1,54 & 0,83 \\
\hline Sección 10 & 1,49 & 0,66 \\
\hline Sección 11 & 1,29 & 0,45 \\
\hline Sección 12 & 1,17 & 0,46 \\
\hline Sección 13 & 1,11 & 0,34 \\
\hline Sección 14 & 1,04 & 0,49 \\
\hline Sección 15 & 1,25 & 0,62 \\
\hline Sección 16 & 1,52 & 0,77 \\
\hline Sección 17 & 1,73 & 1,06 \\
\hline Sección 18 & 1,84 & 1,10 \\
\hline Sección 19 & 1,66 & 1,04 \\
\hline Sección 20 & 1,47 & 0,98 \\
\hline Sección 21 & 1,24 & 0,99 \\
\hline Sección 22 & 1,31 & 0,82 \\
\hline Sección 23 & 2,04 & 1,04 \\
\hline Sección 24 & 1,75 & 1,07 \\
\hline Sección 25 & 1,70 & 0,99 \\
\hline Sección 26 & 1,76 & 0,86 \\
\hline Sección 27 & 1,51 & 0,82 \\
\hline Sección 28 & 1,36 & 0,81 \\
\hline Sección 29 & 1,60 & 0,76 \\
\hline Sección 30 & 1,55 & 0,97 \\
\hline Sección 31 & 1,61 & 0,87 \\
\hline Sección 32 & 1,41 & 0,75 \\
\hline Sección 33 & 1,50 & 0,58 \\
\hline Sección 34 & 1,55 & 0,62 \\
\hline Sección 35 & 1,60 & 0,68 \\
\hline Sección 36 & 1,50 & 0,76 \\
\hline Sección 37 & 1,42 & 0,81 \\
\hline Sección 38 & 1,26 & 0,79 \\
\hline Sección 39 & 1,05 & 0,61 \\
\hline Sección 40 & 1,09 & 0,62 \\
\hline Sección 41 & 1,55 & 0,93 \\
\hline Sección 42 & 1,71 & 0,74 \\
\hline Sección 43 & 1,94 & 0,75 \\
\hline Sección 44 & 1,77 & 0,69 \\
\hline Sección 45 & 1,67 & 0,79 \\
\hline Sección 46 & 2,54 & 0,62 \\
\hline Sección 47 & 2,97 & 0,73 \\
\hline Sección 48 & 2,78 & 0,61 \\
\hline Sección 49 & 2,74 & 0,51 \\
\hline Sección 50 & 2,33 & 0,76 \\
\hline Sección 51 & 2,25 & 0,92 \\
\hline Sección 52 & 2,37 & 0,82 \\
\hline Sección 53 & 2,37 & 0,67 \\
\hline
\end{tabular}

Tabla 4. Secciones en milímetros de los arcos A1 y A2 de la lira.

\subsubsection{La lira}

En la lira se han realizado lecturas en cinco rectas y dos arcos con un total de 485 secciones.

Encontramos los valores máximos de profundidad en las líneas exteriores pero de forma muy relevante en las líneas longitudinales al soporte, lo cual solo puede explicarse por la posición vertical del soporte en el momento de ejecución de la lira y la fuerza impresa por la gravedad derivada de dicha posición. Esta hipótesis queda refrendada al contrastar los datos de las rectas verticales R3 y R5 con las horizontales R2 y R1.

En el trazado de la lira se han tomado medidas de dos rectas y dos arcos paralelas ambas entre sí: R3 con R4 y A1 con A2. En ambos casos los datos muestran que la profundidad del trazado exterior, el que corresponde con el contorno de la lira, es más profundo que el interior. Estas líneas internas fueron hechas posteriormente al silueteado de tal manera que, al igual que ocurría con la decoración del escudo, el tallador tuvo cuidado de evitar saltados en la superficie y explicaría también la baja profundidad de la recta vertical R4.

La secuencia de grabado de la lira se iniciaría con la estela en posición vertical hincada partiendo del contorno exterior. Creemos que por su lado superior derecho, tal como sugería Álvarez (1985:214), lo que nos indica además un probable grabador diestro. Tras grabar el contorno del brazo derecho hasta el inferior de la caja, inició el mismo procedimiento por el lado superior izquierdo hasta encontrarse ambos trazos en la zona de menor profundidad de surco en la parte inferior izquierda. Al acabar el contorno del cuerpo de la lira lo remató con la línea de separación entre el cuerpo superior e inferior y toda la decoración interior. La hipótesis del inicio por el lado derecho se debe a que, si se hubiera iniciado por el lado izquierdo, probablemente el grabador no hubiera perdido el eje con respecto al soporte, en cambio al iniciar la lira a varios centímetros de separación del borde en el lado derecho ya no pudo rectificar y dejó la lira descuadrada para mantener unas proporciones adecuadas. 


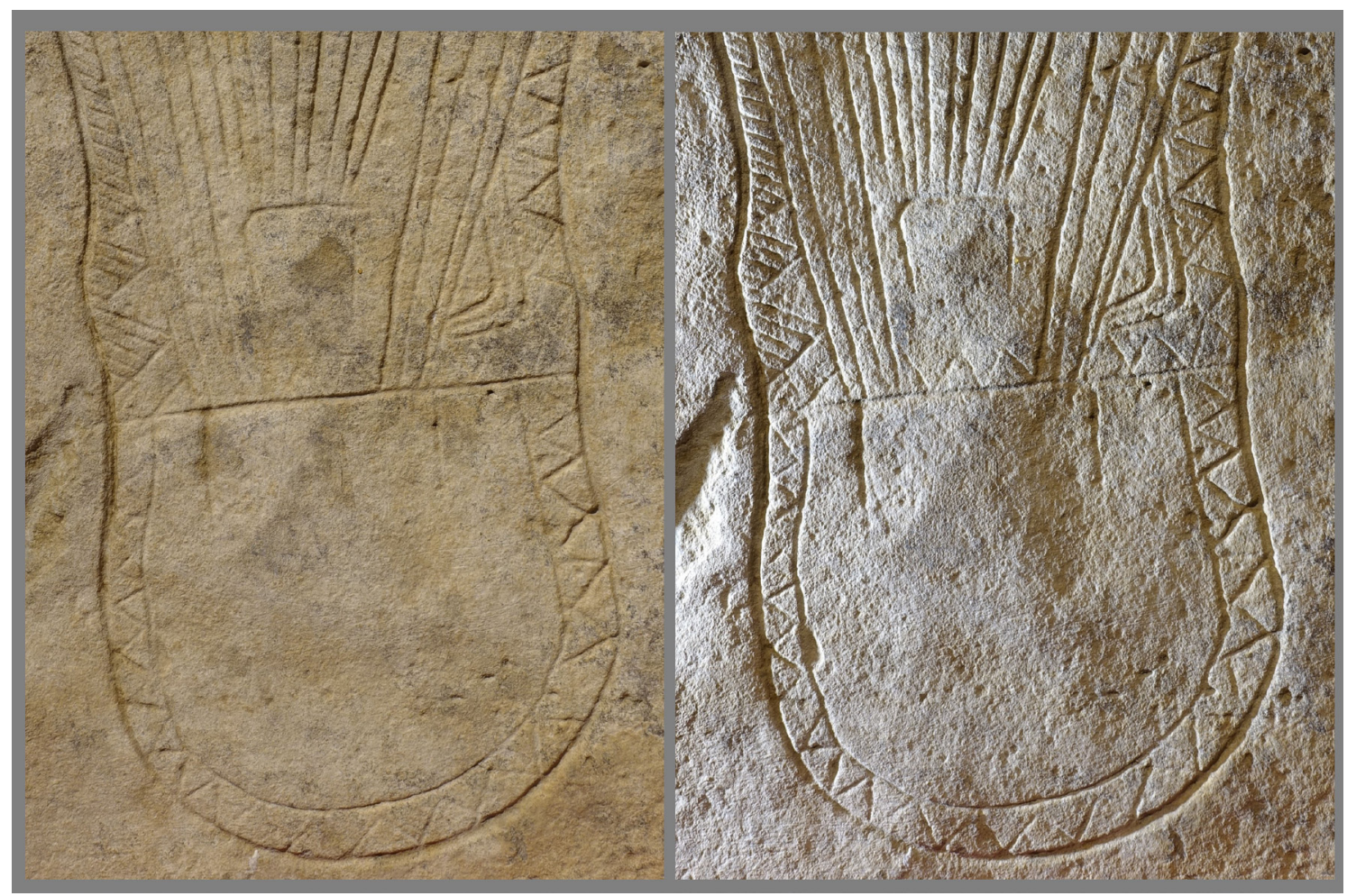

Figura 10. Lira. Detalle del contraste de profundidad de la vertical R3 y la horizontal R1.

Las cuerdas a los lados de la pieza central se realizarían antes que ésta, pero las cuerdas centrales se grabarían después dado que todas ellas parecen dirigirse hacia el centro reduciendo su profundidad al acercarse a la intersección con la pieza central.

Desconocemos la razón por la cual los triángulos de la sección superior de la lira en ambos lados fueron rellenados de líneas mientras que los triángulos decorativos de la parte inferior quedaron vacíos. Esto quizá indique un cambio de material (madera-hueso) en la lira que sirvió de modelo, dado que consideramos que el grabador ha tenido la oportunidad de ver el objeto original aunque, en el momento de la ejecución, pueda estar rememorando su forma y detalles. La disposición de los motivos interiores demuestra la incertidumbre que el grabador tiene respecto a este aspecto del instrumento, si bien el contorno está representado fielmente. No somos partidarios de que el grabador se haya basado en una representación gráfica de lira, sobre todo a juzgar por el detalle de intersección entre brazos y travesaño que denota una comprensión de las partes integrantes del cuerpo del instrumento, totalmente desconocida en los grabados de las liras esquemáticas de los ejemplares del suroeste. 


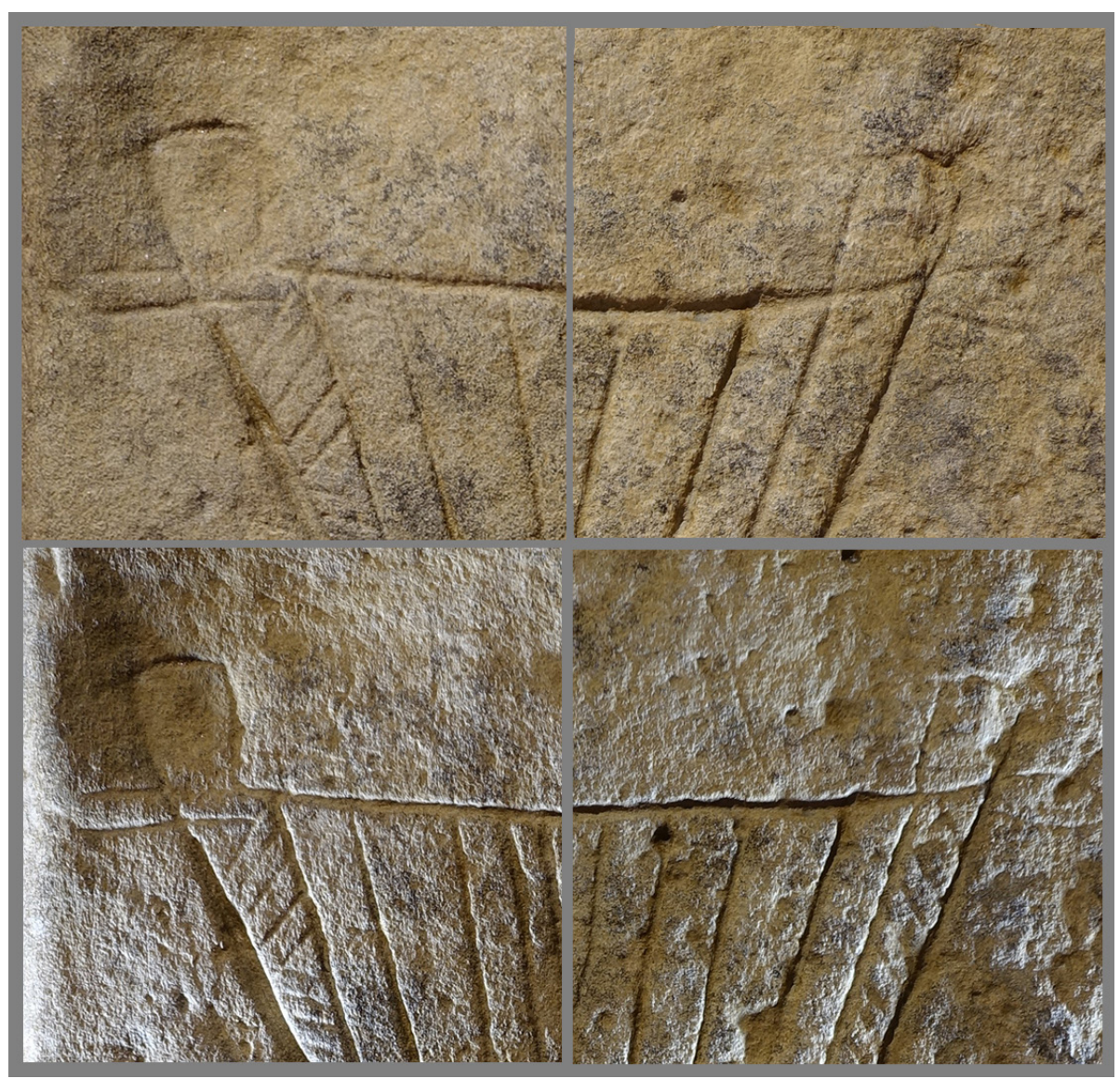

Figura 11. Lira. Detalle de la intersección entre brazo y travesaño.

Dado que la notable diferencia de profundidad entre las rectas verticales y horizontales de la lira pueden explicarse por la posición ya hincada del soporte en el momento de su ejecución, decidimos tomar medidas de las líneas rectas del escudo que se encuentran en posiciones verticales paralelas a las rectas verticales de la lira (R4 y R5) y horizontales paralelas a las rectas también horizontales de la lira (R6 y R7) con el fin de detectar si esta anomalía se presentaba también en el escudo. Pudimos comprobar que no existía ningún contraste relevante entre las cuatro rectas del escudo, lo cual nos lleva a pensar que este motivo fue grabado con el soporte tumbado.

En el caso en que el escudo hubiera sido ejecutado con la estela erecta percibiríamos un contraste de profundidad entre las rectas longitudinales y transversales al soporte.

Es, por tanto, un sólido argumento para defender la ejecución diacrónica de los motivos. 


\begin{tabular}{|c|c|c|c|c|c|c|c|c|c|c|c|c|}
\hline & \multicolumn{5}{|c|}{ LIRA Profundidad (mm) } & \multicolumn{7}{|c|}{ ESCUDO Profundidad (mm) } \\
\hline Seccion & Recta 1 & Recta 2 & Recta3 & Fecte 4 & Fecta 5 & Recta 1 & Recta 2 & Recta 3 & Recta 4 & Recta 5 & Recta 6 & Fecta7 7 \\
\hline Seccion 1 & 0,47 & 0,53 & 3,50 & 1,05 & 1,52 & 1,57 & 1,77 & 2,50 & 1,34 & 2,15 & 1,10 & 1,52 \\
\hline $\sec i \operatorname{lin} 2$ & 0,62 & 0,32 & 3,51 & 0,85 & 1,48 & 1,68 & 1,85 & 2,72 & 1,22 & 2,22 & 1,12 & 1,80 \\
\hline Seccion 3 & 0,75 & 0,22 & 3,51 & 0,78 & 1,51 & 1,74 & 1,91 & 2,78 & 1,27 & 2,23 & 1,13 & 2,75 \\
\hline Seccion 4 & 1,02 & 0,51 & 3,51 & 0.82 & 1,44 & 1,70 & 1,90 & 2,84 & 1,37 & 2,27 & 1,48 & 2,88 \\
\hline Seccion 5 & 1,15 & 0,78 & 3,61 & 0,89 & 1,31 & 1,71 & 1,81 & 3,08 & 1,48 & 2,20 & 1,64 & 3,22 \\
\hline Seccion 5 & 1,24 & 0,97 & 3,69 & 0,89 & 1,32 & 1,74 & 1,75 & 3,18 & 1,45 & 2,11 & 1,73 & 3,40 \\
\hline Sección 7 & 1,24 & 0,85 & 3,60 & 0.99 & 1,35 & 1,83 & 1,81 & 3,19 & 1,51 & 2,03 & 1,78 & 3,62 \\
\hline Seccion 8 & 1,25 & 0,74 & 3,61 & 1,08 & 1,57 & 2,07 & 1,71 & 3,18 & 1,57 & 2,00 & 2,01 & 3,55 \\
\hline Secciong 9 & 1,23 & 0,75 & 3,64 & 1,05 & 1,74 & 2,09 & 1,75 & 3,18 & 1,54 & 2,04 & 2,20 & 3,23 \\
\hline Secoón 10 & 1,21 & 0,88 & 3,57 & 0.95 & 1.85 & 2,20 & 1,71 & 3,22 & 1,45 & 1,95 & 2,59 & 3,22 \\
\hline Secoton 11 & 1,21 & 0,99 & 3,69 & 0,99 & 1,84 & 2,40 & 1,55 & 3,29 & 1,42 & 1,97 & 2,79 & 3,28 \\
\hline Secotón 12 & 1,14 & 1,01 & 3,73 & 1,30 & 1,75 & 2,44 & 1,59 & 3,23 & 1,52 & 2,01 & 2,87 & 3,35 \\
\hline Secoón 13 & 1,12 & 0,71 & 3,78 & 1.27 & 1,72 & 2,39 & 1,61 & 3,30 & 1,67 & 2,00 & 2,94 & 3,56 \\
\hline Secobon 14 & 1,09 & 0,75 & 3,91 & 1,11 & 1,72 & 2,29 & 1,65 & 3,12 & 1,71 & 1,98 & 2,92 & 3,80 \\
\hline Secoón 15 & 1,17 & 0,95 & 3,83 & 1,05 & 1,65 & 2,22 & 1,65 & 2,95 & 1,69 & 1,98 & 2,96 & 3,77 \\
\hline Secobon 15 & 1,13 & 1,08 & 3,78 & 1,00 & 1,61 & 2,22 & 1,74 & 2,85 & 1,61 & 1,85 & 2,97 & 3,56 \\
\hline Secoón 17 & 1,21 & 1,04 & 3,81 & 1,08 & 1,59 & 2,30 & 1,84 & 2,95 & 1,48 & 1,67 & 3,00 & 3,87 \\
\hline Secoón 18 & 1,18 & 1,00 & 3,83 & 1,16 & 1,68 & 2,33 & 1,94 & 3,29 & 1,35 & 1,65 & 2,99 & 3,81 \\
\hline Secoón 19 & 1,21 & 0,95 & 3,87 & 1,09 & 1,98 & 2,30 & 1,95 & 3,59 & 1,25 & 1,79 & 3,00 & 4,07 \\
\hline Secoón 20 & 1,28 & 1,02 & 3,93 & 1,20 & 2,15 & 2,22 & 1,99 & 3,49 & 1,18 & 1,71 & 3,03 & 4,43 \\
\hline Secoón 21 & 1,40 & 1,06 & 4,02 & 1,24 & 2,37 & 2,25 & 1,98 & 3,45 & 1,20 & 1,52 & 3,02 & 3,90 \\
\hline Secoón 22 & 1,44 & 0,92 & 4,08 & 1,15 & 2,35 & 2,32 & 1,99 & 3,06 & 1,34 & 1,50 & 2,79 & 3,64 \\
\hline Secoón 23 & 1,38 & 0,71 & 3,95 & 1,00 & 2,51 & 2,35 & 1,91 & 2,98 & 1,34 & 1,45 & 2,50 & 3,87 \\
\hline Secobon 24 & 1,51 & 0,62 & 3,93 & 0,98 & 2,71 & 2,37 & 1,93 & 3,04 & 1,28 & 1,43 & 2,49 & 4,50 \\
\hline Secoón 25 & 1,57 & 0,62 & 3,90 & 0.88 & 2,94 & 2,39 & 1,82 & 2,89 & 1,35 & 1,45 & 2,37 & 4,16 \\
\hline Secoón 25 & 1,65 & 0,53 & 3,65 & 1,05 & 3,13 & 2,45 & 1,85 & 2,98 & 1,37 & 1,49 & 2,57 & 4,24 \\
\hline Secoón 27 & 1,71 & 0,47 & 3,93 & 1,08 & 3,05 & 2,60 & 1,85 & 2,73 & 1,37 & 1,70 & 2,58 & 4,32 \\
\hline Secoón 28 & 1,83 & 0,58 & 3,93 & 1,08 & 2,95 & 2,59 & 1,88 & 2,74 & 1,49 & 1,73 & 2,56 & 4,52 \\
\hline Secoón 22 & 1,78 & 0,87 & 4,01 & 1,06 & 2,88 & 2,69 & 2,00 & 2,92 & 1,55 & 1,69 & 2,53 & 4,54 \\
\hline Secoón 30 & 1,83 & 0,95 & 3,94 & 0.99 & 2,72 & 2,69 & 2,07 & 3,20 & 1,49 & 1,54 & 2,52 & 4,76 \\
\hline Secoón 31 & 1,92 & 1,21 & 4,10 & 0.87 & 2,56 & 2,54 & 2,27 & 3,09 & 1,57 & 1,47 & 2,44 & 4,81 \\
\hline Secoón 32 & 1,77 & 1,30 & 3,98 & 0,54 & 2,42 & 2,54 & 2,35 & 3,30 & 1,69 & 1,52 & 2,41 & 4,20 \\
\hline Secoón 33 & 1,63 & 1,22 & 4,18 & 0,81 & 2,41 & 2,58 & 2,41 & 3,53 & 1,60 & 1,53 & 2,52 & 4,38 \\
\hline Secoton 34 & 1,52 & 0,85 & 4,06 & 0,84 & 2,41 & 2,62 & 2,35 & 3,54 & 1,53 & 1,58 & 2,45 & 4,25 \\
\hline Secoón 35 & 1,35 & 0,85 & 4,01 & 0,91 & 2,23 & 2,63 & 2,22 & 3,50 & 1,35 & 1,57 & 2,34 & 4,69 \\
\hline Secoón 35 & 1,25 & 0,95 & 3,98 & 0,82 & 2,18 & 2,50 & 2,07 & 3,54 & 1,40 & 1,57 & 2,30 & 4,51 \\
\hline Secoón 37 & 1,35 & 1,03 & 3,91 & 0,77 & 2,25 & 2,48 & 1,90 & 3,69 & 1,45 & 1,57 & 2,25 & 4,68 \\
\hline Secoón 38 & 1,32 & 1,01 & 3,93 & 0.98 & 2,31 & 2,59 & 1,84 & 3,62 & 1,38 & 1,48 & 2,27 & 4,18 \\
\hline Secoón 39 & 1,45 & 0,95 & 3,79 & 1,13 & 2,25 & 2,57 & 1,80 & 3,39 & 1,35 & 1,44 & 2,25 & 3,94 \\
\hline Secobon 40 & 1,51 & 0,91 & 3,65 & 1,07 & 2,32 & 2,62 & 1,80 & 3,23 & & & 2,15 & 3,85 \\
\hline Secodón 41 & 1,58 & 0,71 & 3,55 & 0,95 & 2,39 & 2,72 & 1,78 & 3,18 & & & 2,21 & 4,38 \\
\hline Secolón 42 & 1,59 & 0,51 & 3,59 & 0,90 & 2,39 & 2,78 & 1,73 & 3,10 & & & 2,21 & 3,92 \\
\hline Secoón 43 & 1,48 & 0,49 & 3,52 & 0.85 & 2,52 & 2,54 & & 3,08 & & & 2,14 & 3,52 \\
\hline Secoón 44 & 1,29 & 0,61 & 3,39 & 0.85 & 2,59 & 2,48 & & 2,95 & & & 1,95 & 3,88 \\
\hline Secotón 45 & 1,20 & 0,57 & 3,37 & 1,06 & 2,55 & 2,40 & & 2,89 & & & 1,75 & 4,02 \\
\hline Secoón 45 & 1,25 & 0,72 & 3,32 & 1,12 & 2,57 & 2,42 & & & & & 1,71 & 4,05 \\
\hline Secoón 47 & 1,19 & 0,73 & 3,28 & 1,15 & 2,55 & 2,35 & & & & & & 3,73 \\
\hline Secobon 48 & 1,13 & 0,75 & 3,12 & 1,18 & 2,74 & 2,58 & & & & & & 4,35 \\
\hline Secoón $\triangle 9$ & 1,11 & 0,82 & 2,95 & 1,03 & 2,88 & 2,54 & & & & & & 4,65 \\
\hline Secoón 50 & 1,23 & 0,91 & 2,80 & 0.95 & 3,03 & & & & & & & \\
\hline Secobon 51 & 1,07 & 0,98 & 2,75 & 1,38 & 3,09 & & & & & & & \\
\hline Secoón 52 & 1,04 & 0,93 & 2,79 & 1,21 & 3,07 & & & & & & & \\
\hline Secoón 53 & 1,01 & 0,97 & 2,71 & 1,22 & 3,10 & & & & & & & \\
\hline Secodón 54 & 1,05 & 1,17 & 2,54 & 1,07 & 3,05 & & & & & & & \\
\hline
\end{tabular}




\begin{tabular}{|c|c|c|c|c|c|}
\hline & \multicolumn{5}{|c|}{ URA Profundidad $(\mathrm{mm})$} \\
\hline Sección & Recta 1 & Recta 2 & Recta 3 & Recta 4 & Recta 5 \\
\hline Sección 55 & 1,12 & 1,26 & 2,43 & 0,98 & \\
\hline Sección 56 & 1,13 & 1,07 & 2,39 & 0,90 & \\
\hline Sección 57 & 1,14 & 0,80 & 2,42 & 0,81 & \\
\hline Sección 58 & 1,12 & 0,56 & 2,49 & 0,85 & \\
\hline Sección 59 & 1,33 & 0,51 & 2,50 & 0,82 & \\
\hline Sección 60 & 1,57 & 0,27 & 2,53 & 0,78 & \\
\hline Sección 61 & 1,65 & 0,16 & 2,54 & 0,76 & \\
\hline Sección 62 & 1,79 & 0,10 & 2,67 & 0,77 & \\
\hline Sección 63 & 2,03 & 0,30 & 2,57 & 0,76 & \\
\hline Sección 64 & 2,04 & 0,39 & 2,59 & 0,75 & \\
\hline Sección 65 & 1,96 & 0,59 & 2,49 & 0,74 & \\
\hline Sección 66 & 1,78 & 0,66 & 2,48 & 0,90 & \\
\hline Sección 67 & 1,63 & 0,71 & 2,44 & 1,00 & \\
\hline Sección 68 & 1,59 & 0,73 & 2,36 & 1,25 & \\
\hline Sección 69 & 1,57 & 0,63 & 2,33 & 1,08 & \\
\hline Sección 70 & 1,50 & 0,61 & 2,31 & 0,85 & \\
\hline Sección 71 & 1,40 & 0,70 & 2,24 & 0,70 & \\
\hline Sección 72 & 1,31 & 0,79 & 2,18 & 0,56 & \\
\hline Sección 73 & 1,24 & 0,81 & 2,24 & 0,49 & \\
\hline Sección 74 & 1,10 & 1,00 & 2,31 & 0,40 & \\
\hline Sección 75 & 1,03 & 0,91 & 2,32 & 0,66 & \\
\hline Sección 76 & $1, \infty$ & 0,74 & 2,30 & 0,75 & \\
\hline Sección 77 & 0,98 & 0,64 & 2,38 & 0,71 & \\
\hline Sección 78 & 0,91 & 0,73 & 2,42 & 0,77 & \\
\hline Sección 79 & 0,93 & 0,80 & 2,40 & 0,24 & \\
\hline
\end{tabular}

Tabla 5.Comparativa de secciones en milímetros de las rectas de lira (R1-5) y escudo (R1-7).

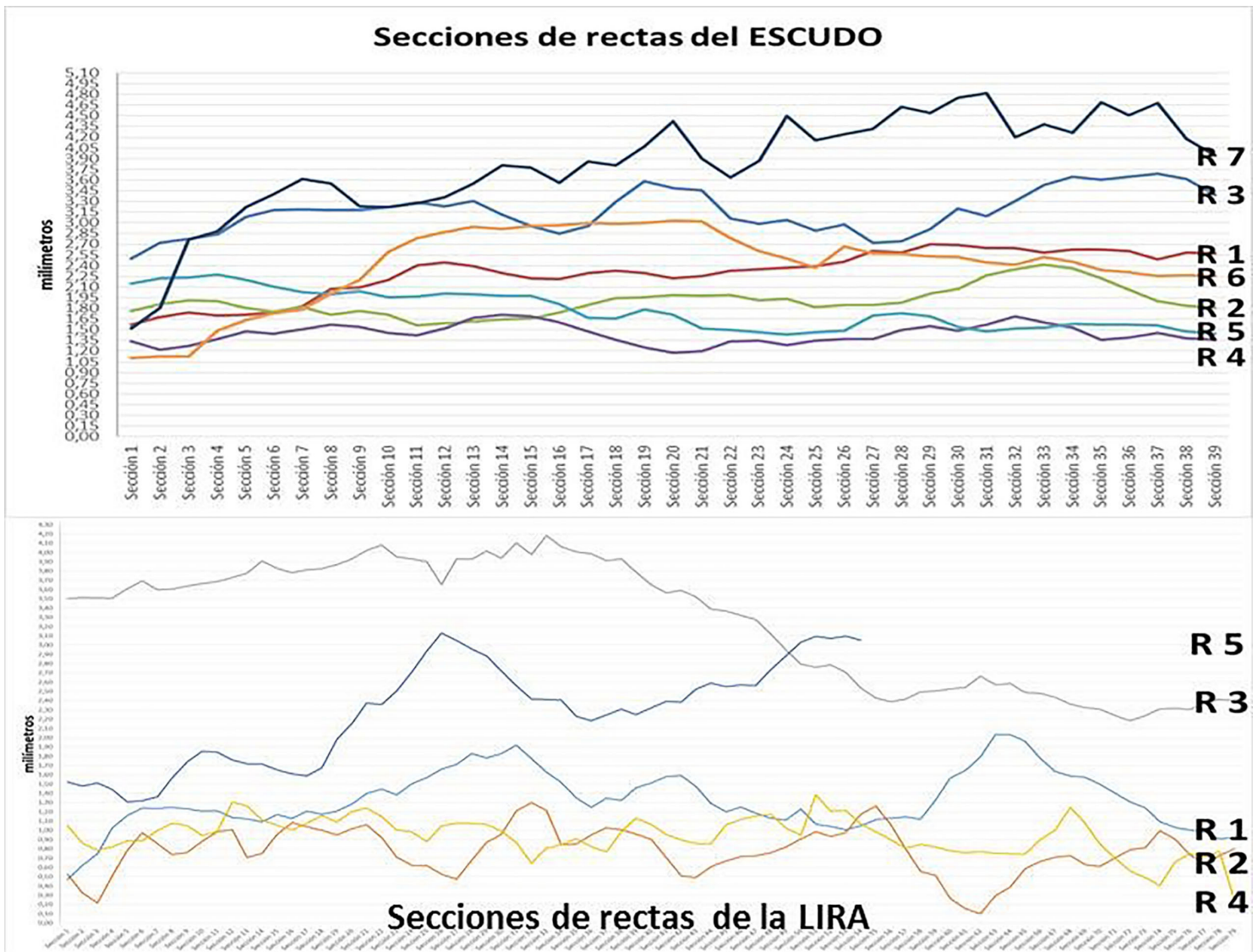

Figura 12. Gráfica comparativa de la profundidad de las rectas estudiadas en escudo y lira. Destaca la profundidad de las rectas R3 y R5 de la lira, en sentido longitudinal al eje de la estela. 


\section{Discusión}

Las conclusiones extraídas de la lectura arqueométrica de las mediciones de profundidad de tramos del grabado sobre un modelo digitalizado, y de la composición de los motivos sobre el soporte entra de lleno en la problemática de las estelas del suroeste. Creemos que tanto el método utilizado como la lectura de los datos resultan relevantes ya que permiten una mayor solidez probatoria en el uso de conceptos como el de reutilización, sincronía-diacronía de motivos o en aspectos como la posición del soporte, facetas todas ellas interrelacionadas. Respecto a la cuestión de la reutilización de una estatua -menhir propuesta por Díaz-Guardamino (2010:133,177,190,341: figura 202,372,433) debemos tener en cuenta que el soporte, si bien de silueta antropomorfa, fue preparado para ser contemplado únicamente por la cara de los grabados, su parte trasera aparece en bruto y sin motivos, por lo que su silueta es el resultado de una preparación específica en la que se pretende generar un lienzo sobre el que grabar unos motivos por una única cara, e incidir en esta misma fase en el antropomorfismo, dado que se pulen los hombros y los laterales. El soporte está tan condicionado por esta cuestión que podemos denominar bidimensional, que, aunque la estatua-menhir hubiera sido muy transformada, pensamos que el creador no podría haber evitado la presencia de "restos de un pasado tridimensional". No obstante, la aplicación de la técnica RTI podría aportar información sobre trazos que no se ven a simple vista. El creador ejecuta el grabado del escudo en una perfecta simetría con respecto al soporte pero también en un aprovechamiento tal de la superficie pulimentada, en lo que respecta a la anchura, que dificulta considerar la fase de preparación del soporte y la de ejecución del escudo, como obra de dos manos y dos momentos diferentes. No creemos que exista una fase de la estela de Luna-Valpalmas anicónica tal como señala Díaz-Guardamino (2010:132: fig.79, 341: fig.202). A la luz de todo ello creemos que la relación entre antropomorfismo del soporte y estatuas-menhir no debería generalizarse, incluso la relación entre antropomorfismo y arcaísmo dentro de la serie debe tratarse con cautela. En otro ejemplar como Talavera de la Reina es clara la reutilización de un soporte previo, dado que los motivos representados no tienen relación compositiva con el soporte, en este caso hay un grabado de tipo A sobre un soporte an- tropomorfo tridimensional y resultaría de gran interés aplicar el estudio de profundidad de grabado contrastando el antropomorfo con los rasgos faciales. Otro ejemplar problemático e interesante por su adscripción a la llamada zona marginal es Substantion. Los perfiles decorados con motivos geométricos le aportan cierto grado de tridimensionalidad que Harrison (2004: 314) resuelve proponiendo la reutilización de una estela calcolítica, observando diferencias en el tipo de grabado de los motivos geométricos con respecto al resto. Para confirmar o desmentir esto sería necesario un análisis mediante digitalización 3D. No obstante, en ningún caso es antropomorfa. El hecho de que la lira de la estela de Luna-Valpalmas fuera realizada con el soporte en posición vertical permite sugerir la diacronía entre motivos, pero no soluciona el lapso cronológico transcurrido entre ambos, si bien el preparado de la superficie y el escudo fueron realizados en posición horizontal, por comodidad técnica a la hora de trazar las circunferencias, no consideramos que la estela tuviera una vida útil horizontal, sino que fue erguida a continuación. No obstante, a la luz de la secuencia propuesta por la lectura de los datos, la hipótesis de la relación losa sepulcral horizontal-estela básica de Celestino sobrevive (2001), más teniendo en cuenta que la parte trasera no posee evidencias de preparado mediante abrasión. Ahora bien, el hecho de que la lira fuera realizada estando la estela en posición vertical suscribe también la opinión de Galán (1994) respecto a que a la pieza le faltaría un fragmento en la base, dado que en caso contrario la lira habría quedado bajo tierra. Consideramos estas dos conclusiones de enorme relevancia dado que la realización del escudo en posición horizontal y la lira en posición vertical, según la lectura ofrecida, concilia las opiniones de ambos autores respecto a la estela de Luna-Valpalmas: La estela pudo ser una losa horizontal en su fase básica sin objeto adicional, opinión esgrimida por Celestino, pero le falta un fragmento en la base porque si no, la lira quedaría bajo tierra, opinión defendida por Galán y que suscribimos, dado que la lira fue realizada con la estela erguida. Harrison admite la hipótesis de Celestino para los casos con escudo en posición central cuyos demás motivos ocupan toda la superficie de la losa, pero señala casos, como Baraçal o Ibahernando, en que:

were intended as vertical monuments since they have the lower half of the stone free of mo- 
tifs and perfectly adapted as a footing (Harrison, 2004:88).

Es el caso también de Buoux I y tal vez de Aldea del Rey, que, aunque ha perdido la parte superior, presenta un apuntamiento en la inferior. El lapso transcurrido entre el grabado del escudo y el de la lira es difícil de determinar pero existe, ya que la misma mano habría grabado la lira a continuación del escudo en posición horizontal, y habría respetado el eje de simetría del soporte, aunque pudiera haber cambiado de herramienta. Creemos que el lapso no puede ser muy extenso dado que la similitud entre la decoración mediante triángulos de ambos motivos remite a un imaginario común que completa la escena de forma armónica. La decoración mediante triángulos rayados y sin rayar hace su aparición en el Valle del Ebro de forma destacada sobre las cerámicas excisas fundamentalmente de perfil bitroncocónico en el Bronce Final, y se prolonga en el tiempo de forma repetitiva y masiva sobre cerámicas globulares de cuello cilíndrico mediante la aplicación de pigmentos postcocción en la Edad del Hierro I ${ }^{13}$.

La herramienta usada en el grabado de la lira parece ser la misma que en el trazo de la barbilla y hace más compleja la secuencia de elaboración de los grabados ya que el grabador de la lira resaltaría el aspecto antropomorfo del soporte. No obstante, para determinar con certeza la sección rectangular, cuadrada o circular de los cinceles utilizados será necesario realizar un estudio experimental sobre el que ya se está trabajando ${ }^{14}$. La dureza del soporte permite el trabajo con cinceles de bronce de escasa dureza. Recientemente Araque (2018: 189, tab.1) ha planteado que determinados soportes de diorita, cuarcita, granito y basalto solo podrían ser grabados con cinceles de hierro, dando un valor absoluto de dureza a los metales y a los soportes. Sin embargo, los estudios arqueometalúrgicos experimentales centrados en aleaciones de base $\mathrm{Cu}$ defienden desde hace tiempo, que si bien la dureza de la herramienta depende en gran medida de las proporciones en la adición de Sn dentro de unos límites, 5-10\%, son fundamentalmente los tratamientos de posprocesado: forja en frío, recocido y martillado los que incrementan la dureza en la escala Vickers (Cathro, 2005, Murillo-Barroso et al. 2014). Aunque la asociación de cinceles de hierro muy antiguos en la Beira Interior, cerca de lugares de aparición de estelas en soportes duros pueda ser una hipótesis sugerente, como señala Araque (2018:189), resulta necesaria la experimentación con cinceles de bronce endurecidos mediante tratamiento de forja en frío, recocido y martillado sobre soportes duros para confirmar o rebatir dicha propuesta.

\section{Reflexión final}

El estudio arqueométrico realizado sobre la estela de Luna-Valpalmas nos permite proponer una secuencia de la creación de dicha pieza: sobre un bloque de arenisca local se preparó un soporte antropomorfo puliendo una de sus caras y ambos laterales. A continuación, se grabó el escudo en perfecta simetría con la superficie que previamente se había dispuesto para tal fin. Este proceso comenzó por la tercera circunferencia, continuó por el resto de círculos y culminó con los triángulos decorativos. Posteriormente, la estela se colocó en posición vertical y con otra herramienta se inició el grabado de la lira probablemente por su esquina superior derecha, se continuó la silueta hasta el inferior de la caja y se realizó el mismo procedimiento desde la zona superior izquierda, encontrándose ambos surcos en la parte inferior izquierda. Se grabó el travesaño para completar el perfil y finalmente se incluyeron los motivos interiores. Deducimos de la diferencia de surco entre ambos motivos y de posición de grabado respecto al eje la mano de dos grabadores sin poder precisar el lapso transcurrido entre uno y otro. Sin duda, el hecho de que la lira fuera

13 Conocemos bien el cénit de estas segundas producciones en la transición entre los siglos VIII y VII a.C., dado que son el elemento vascular más característico del Hierro I en el Valle Medio del Ebro, y que nos ofrecería el límite ante quem. Resulta más difícil ahondar en la génesis de los motivos excisos, aunque recientemente se ha realizado un intento de aproximación a través de la aplicación de estadística bayesiana a dataciones absolutas, en contextos Cogotas y Campos de Urnas (Aranda-Contamina y Rodanés, 2019). La amplia horquilla temporal nos lleva desde el siglo XIV a.C. para las primeras, lo que nos ofrecería el límite post quem, con la transición entre ambas fases en torno al siglo XII-XI a.C. y el final en torno al siglo VIII a.C. Durante prácticamente todos estos siglos encontramos también los triángulos sobre vasijas de almacenaje a base de apliques plásticos en ocasiones digitados.

14 Se han realizado pruebas de grabado sobre arenisca procedente del lugar de aparición de la estela con cinceles de sección cuadrada y redonda experimentales con aleaciones de $90 \% \mathrm{Cu}-10 \% \mathrm{Sn}$, proporciones habituales en el Bronce Final, sin utilización de técnicas de postprocesado. Los resultados todavía inéditos han proporcionado huellas de profundidad de surco de grabado muy similares a las del ejemplar original. 
realizada con la estela erecta y, ante la imposibilidad de que ésta quedara bajo tierra, hace obligatoria la existencia de un fragmento perdido en la base de la pieza. Se deben establecer elementos de comparación entre las estelas de la llamada zona marginal o noreste (Luna-Valpalmas, Buoux I, Buoux II y Substantion) siendo el más destacado la decoración adicional y la monumentalidad. La estela de Baraçal y la de Substantion están realizadas con la técnica del relieve, característica que comparten con las estelas alentejanas, consideradas de forma unánime anteriores a las estelas del suroeste. Ello podría indicar un rasgo de arcaísmo para este grupo y una posible pertenencia a un mis- mo taller. Otro elemento que comparten las cuatro estelas básicas del noreste, en este caso también la de Luna-Valpalmas, es que el escudo muestra el umbo en lugar de la abrazadera, al igual que ocurre con las estelas básicas de Tojais y Baraçal, en zonas relativamente septentrionales y el ejemplar de Toya en Jaén. La inversión del escudo en la representación es un hecho que sin lugar a dudas está cargado de significado. Los resultados obtenidos ahondan en la necesidad de considerar las estelas como piezas con una biografía propia y compleja que reflejan los cambios que tienen lugar en las comunidades que las producen, en este caso el noreste peninsular.

\section{Bibliografía}

Andrés Rupérez, T. (2014): El sabio generoso en la estela de Luna. Miscelánea de estudios en homenaje a Guillermo Fatás Cabeza. Institución Fernando el Católico. Zaragoza: 95-104.

Almagro Basch, M. (1966): Las estelas decoradas del suroeste peninsular. Biblioteca Praehistorica Hispana VIII, Consejo superior de investigaciones científicas. Instituto español de prehistoria. Madrid.

Almagro Gorbea, M. (1977): El Bronce Final y el Período Orientalizante en Extremadura. Biblioteca Praehistorica Hispana XIV, Consejo superior de investigaciones científicas. Instituto español de prehistoria Madrid.

Almagro Gorbea, M. (1992): Los intercambios culturales entre Aragón y el litoral mediterráneo durante el bronce final en Aragón litoral mediterráneo. Intercambios culturales durante la prehistoria. Institución Fernando el Católico, Zaragoza: 633-658.

Almagro Gorbea, M. (2002): Tartessos una cultura literaria: textos, iconografía y arqueología. Bolskan: Revista de de arqueología del Instituto de estudios altoaragoneses. 19. Huesca:15-33.

Álvarez Martínez, R. (1985): Presunto origen de la lira grabada en una estela funeraria (Ca. S. VIII a.C) encontrada en Luna (Zaragoza). Revista de Musicología VIII 2: 207-228.

Álvarez Martínez, R. (1990): Las liras prehistóricas de Luna (Zaragoza) y de Saint-Symphorien de Paule (Bretaña).Testimonios de una misma tipología en el bronce final y en la Tène. Archaeologiamusicalis III-IV.

Alves, L. y Reis, M. (2011): Memoriais de pedra, símbolos de Identidade. Duas novas peças escultóricas de Cervos (Montalegre, Vila Real) en Estelas e estatuas-menhires da Pré à Protohistória. Actas IV Jornadas Raianas (Sabugal, 2009). Raquel Vilaça (coord.). Sabugal: 187-216.

Aranda-Contamina; P. y Rodanés Vicente, J.M. (2019): La decoración excisa como indicador de procesos de interacción e intercambio durante el Bronce Final en el valle medio del Ebro. Reflexiones a partir de nuevos hallazgos y dataciones absolutas. Trabajos de Prehistoria, 76-1: 84-101. https://doi. org/10.3989/tp.2019.12227.

Araque González, R. (2018): Inter-Cultural Communications and Iconography in the Western Mediterranean during the Late Bronze Age and the Early Iron Age. Freiburger Archaeölogische Studien. Band 9. Leidorf. https://doi.org/10.1017/eaa.2020.13.

Arenas, C. (1993): Sedimentología y paleogeografia del Terciario del margen pirenaico y sector central de la Cuenca del Ebro (zona aragonesa occidental), Tesis doctoral (inédita), Universidad de Zaragoza: 858.

Barceló i Alvarez, J. A. (1989): Arqueología, lógica y estadística: Un análisis de las estelas de la Edad del Bronce en la Península Ibérica. Tesis doctoral, Universitat Autónoma de Barcelona. http://hdl.handle. net/10803/5521.

Bendala Galán, M. (1977): Notas sobre las estelas decoradas del suroeste y los orígenes de Tartessos. Habis 8: 177-205. 
Bendala Galán, M. (1983): En torno al instrumento musical de la estela de Luna (Zaragoza). Homenaje al profesor Martín Almagro Basch. Vol II. Madrid: 141-146.

Blázquez, J. M. (1983): Las liras de las estelas hispanas de finales de la Edad del Bronce y su origen fenicio. Archivo español de arqueología, 56: 213-228.

Cathro R. J. (2005): Tin deposits and early history of bronze CIM Magazine Vol 98. № 1088.

Celestino Pérez, S. (1990): Las estelas decoradas del SW peninsular. En la cultura tartésica y Extremadura. Cuadernos emeritenses 2: 45-62.

Celestino Pérez, S. (2001): Estelas de guerrero y estelas diademadas. La precolonización y la formación del mundo tartésico. Bellaterra arqueología. Barcelona.

Celestino Pérez, S. y López Ruiz, C. (2006): New light on the warrior stelae from Tartessos (Spain), Antiquity, Vol 80 No 307: 89-101 https://doi.org10.1017/S0003598X00093285.

Celestino Pérez, S. y Salgado Carmona, J. A. (2011): Nuevas metodologías para la distribución espacial de las estelas del Oeste peninsular en Estelas e estátuas-menhires: Da Pré-à Proto-história. Actas IV Jornadas Raianas. (Sabugal, 2009). Raquel Vilaça (coord.) Sabugal: 417-442.

Conget Vicente, H. y García-Arilla Oliver, A. 2017: La estela de Luna-Valpalmas en su contexto territorial: Primera campaña de prospecciones geomagnéticas en la Tiñica del Royo. Salduie. Estudios de Prehistoria y Arqueología, 17: 143-160.

Díaz-Guardamino Uribe, M. (2010): Las estelas decoradas en la prehistoria de la Península Ibérica. Tesis doctoral. Universidad Complutense. Madrid. https://eprints.ucm.es/id/eprint/11070/.

Díaz-Guardamino Uribe, M. 2020: Rock art as process: Iberian Late Bronze Age 'warrior' stelae in-themaking. In Back Danielsson, I.-M. and A.M. Jones (eds.) Images in-the-making: Art, Process, Archaeology (Social Archaeology and Material Worlds). Manchester: Manchester University Press. https://doi. org/10.7765/9781526142856.00014

Díaz-Guardamino Uribe, M. y Wheatley, D. (2013): Rock art and digital technologies:The application of reflectance transformation imaging (RTI) and 3D laser scanning to the study of late bronze age iberian stelae. Menga. Año 3 Nº 4 : 187-203.

Díaz-Guardamino Uribe, M.; Wheatley, D.; García Sanjuán, L.; Rodriguez Zamora, V. (2015): RIT and the study of engraved rock art: a re-examination of the Iberian southwestern stelae of Setefilla and Almadén de la Plata 2 (Seville, Spain). Digital Applications in Archaeology and Cultural Heritage, 2: 41-54. https://doi.org/10.1016/j.daach.2015.07.002.

Díaz-Guardamino, M.; García Sanjuán, L.; Wheatley, D. W.; Lozano Rodríguez, J. A.; Rogerio Candelera, M. A.; Krueger, M.; Hunt Ortiz, M.; Murillo-Barroso, M.; Balsera Nieto, V. (2019): Rethinking Iberian 'warrior' stelae: a multidisciplinary investigation of Mirasiviene and its connection to Setefilla (Lora del Río, Seville, Spain). Archaeological and Anthropological sciences, 11: 6111-6140 https://doi. org/10.1007/s12520-019-00909-1.

Enríquez Navascués, J. J. y Fernández Algaba, M. (2010): Notas sobre las técnicas de grabado y composición formal de las estelas diademadas y de guerreros. Cuadernos de Arqueología de la Universidad de Navarra. 18: 149-175.

Fatás, G. (1975): Una estela de guerrero con escudo escotado en "V" aparecida en las Cinco Villas de Aragón. Pyrenae 11: 165-169.

Fatás, G. (1983): La estela de guerrero aparecida en "La Tiñica" (Luna, Zaragoza). Suessetania 3, Ejea de los Caballeros.

Galán Domingo, E. y Ruiz-Gálvez, M.L. (1991): Las estelas de guerrero como hitos de vías ganaderas y rutas comerciales. Trabajos de Prehistoria, 48: 258-273 https://doi.org/10.3989/tp.1991.v48.i0.524.

Galán Domingo, E. (1994): Estelas, paisaje y territorio en el Bronce Final del Suroeste de la Península Ibérica. Complutum extra 3: 15-110.

García Sanjuán, L.; Weathley, D. W.; Fábrega Álvarez, P.; Hernández Arnedo M. J.; Polvorinos del Río, A. (2006): Las estelas de guerrero de Almadén de la Plata (Sevilla). Morfología, tecnología y contexto. Trabajos de Prehistoria 63-2:135-152. https://doi.org/10.3989/tp.2006.v63.i2.21.

Gomá Rodriguez, J. L. (2018): El bronce final y la protocolonización en la Península Ibérica. Tesis doctoral. Universidad complutense. Madrid. https://eprints.ucm.es/id/eprint/48192/1/T40069.pdf

Harrison, R. J. (2004): Symbols and Warriors. Images of the European Bronze Age. Western Academic \& Specialist Press Limited. Bristol.

Jiménez Pasalodos, R. (2012): The lyres of the Far West. Chordophones in the bronze age warrior stelae of the southwest iberian Peninsula. Studien zur Musikarchäologie: 8: 215-225. 
Lopez Amador, J. J.; Ruiz Mata, D.; Ruiz Gil, J. A. (2008): El entorno de la bahía de Cádiz a finales de la Edad del Bronce e inicios de la Edad del Hierro. Revista atlántica-mediterránea de prehistoria y arqueología social. 10: 215-236.

Martín Benito, J. I. (2010): Una estela de la Edad del Bronce en Robleda (Salamanca). Ciudad Rodrigo. Carnaval del Toro 2010: 339-342.

Mederos Martín, A. (1996): Representaciones de liras en las estelas decoradas del Bronce Final de la Península Ibérica. CuPAUAM 23:114-123.

Mederos Martín, A. (2012): El origen de las estelas decoradas del suroeste de la Península Ibérica en el Bronce Final II (1325-1150 a. C). En J. Jiménez Ávila (ed). Sidereum Ana II: El río Guadiana en el Bronce Final. Anejos de AEspA LXII: 417-454

Monsalud, Marqués de (1898): Epigrafía romana de Aragón y Extremadura. Boletín de la Real Academia de la Historia, XXXIII.

Montero Ruiz, I., Rodríguez Alcalde, A., Vincent García, J.M., Cruz Berrocal, M. (1998): Técnicas digitales para la elaboración de calcos de arte rupestre, Trabajos de Prehistoria 55-1: 155-169 https://doi. org/10.3989/tp.1998.v55.11.323.

Montero, Ruiz, I., García Heras, M., López-Romero, L. (2007). Arqueometría: Cambios y tendencias actuales, Trabajos de Prehistoria 64, No 1: 23-40 https://doi.org/10.3989/tp.2007.v64.i1

Moreno Arrastio, F. J. (1998): Sobre la obviedad, las estelas decoradas y sus agrupaciones. Gerión. Revista De Historia Antigua 16: 49-84.

Müller, A.; Bouville, C.; Lambert, L. (1988): Provence: Les stèles gravées de l'âge du bronze. Archèologia, 236: 58-63.

Murillo-Barroso, M.; Aranda Jimenez, G.: Montero Ruiz, I. (2014): Aspectos sociales del cambio tecnológico: nuevos datos para valorar la introducción de la aleación del bronce en las sociedades argáricas. En Movilidad, contacto y cambio. II Congreso de Prehistoria de Andalucía: 417-427.

Pettijohn, F.J.; Potter, P.E.; Siever, R. (1987): Sand and Sandstone. Springer-Verlag, New York: 553. Rosso de Luna, M. (1898): Lápida sepulcral de Solana de Cabañas, en el partido de Logrosán (Cáceres). Boletín de la Real Academia de la Historia XXXIII, Madrid: 179-182.

Ruiz-Gálvez, M. L.y Galán Domingo, E. (1991): Las estelas del suroeste como hitos de vías ganaderas y rutas comerciales. Trabajos de Prehistoria, 48: 253-273. https://doi.org/10.3989/tp.1991.v48.i0.524.

Ruiz-Gálvez, M. L. (2019): De hombre y dioses: la estela de guerrero de Magacela y el RP'UM. Un periplo docente e investigador. Estudios en homenaje al profesor Antonio Tejera Gaspar, Chavez Alvarez et al. (coord). Universidad de La Laguna: 463-480.

Salazar, A.; Costa, J.M.; Navarro J.J.; Simón, J.L.; Gracia, J.; Rodríguez Santisteban, R.; García Villar, A.; Solá, J.; del Olmo, A.; Hernández, A.; Ramírez del Pozo, J.; Cuenca, G. (1995): Mapa Geológico de España 1:50.000, hoja $n^{\circ} 284$ (Ejea de los Caballeros) y memoria. IGME, Madrid.

Santos-Estévez, M.; Mañana Borrazás, P.; Amado Rolán, N. Pires, H. (2017): La estela de guerrero y la estela antropomorfa de Pedra Alta (Castrelo de Val, Galicia). Complutum 28(1):71-86 http://dx.doi. org/10.5209/CMPL.58422.

Santos Cancelas, A. (2015): La música de las estelas: liras, identidad y memoria en el suroeste peninsular del Bronce Final. Revista de Musicología, vol.XXXVIII, No1: 17-45 https://doi.org/10.2307/24878246.

Song Zhang y Peisen S. Huang (2006): High-resolution, real-time three-dimensional shape measurement. Optical Engineering 45(12): 123601-08 https://doi.org/10.1117/1.2402128.

Subías, I.; Fernández Nieto, C.; González López, J.M. (1989): Mineralogía de las areniscas cupríferas de Biel (Zaragoza). Boletín de la Sociedad Española de Mineralogía, 12: 315-327.

Tejera Gaspar, A. y Fernández Rodríguez, J (2012): Los dioses de los tartesios. Bellaterra arqueología, Barcelona.

Varela y Pinho (1977): Las estelas decoradas do Pomar (Beja-Portugal), estudio comparado. Trabajos de Prehistoria 34-1: 165-214. 